\title{
Effect of grain growth on cation exchange between dunite and fluid: implications for chemical homogenization in the upper mantle
}

\section{Tomohiro Ohuchi $^{1) *}$, Michihiko Nakamura ${ }^{2)}$ and Katsuyoshi Michibayashi ${ }^{3)}$}

1) Geodynamics Research Center, Ehime University, Matsuyama 790-8577, Japan

2) Department of Earth Science, Graduate School of Science, Tohoku University, Sendai 980-8578, Japan

3) Institute of Geosciences, Shizuoka University, Shizuoka 422-8529, Japan

*Corresponding author

Phone: +81-89-927-8151

FAX: +81-89-927-8167

E-mail: ohuchi@sci.ehime-u.ac.jp 


\section{Abstract}

The effect of grain growth on the cation exchange between synthesized forsterite aggregates (i.e., dunite) and Ni-rich aqueous fluid was evaluated experimentally at 1.2 $\mathrm{GPa}$ and $1200{ }^{\circ} \mathrm{C}$. The grain boundary (GB) migration caused Ni-enrichment in the area swept by the GBs, in a fashion similar to that reported for stable isotope exchange in the quartz aggregates. The progress of the grain growth resulted in an increase in the average nickel concentration in the dunites of up to $\sim 80$ times that calculated for a system having stationary GBs. The overall diffusivity of the nickel along the wet GBs and interconnected fluid networks was found to be $6.5 \cdot 10^{-19}-6.7 \cdot 10^{-18} \mathrm{~m}^{3} / \mathrm{s}$, which is 4-5 orders of magnitude higher than the grain boundary diffusivity in the dry dunite. These results show that the grain growth rate is a fundamental factor in the evaluation of the time-scale of chemical homogenization in the upper mantle.

Keywords: grain growth; grain boundary migration; grain boundary diffusion; forsterite; nickel

\section{Introduction}

Grain boundaries (GBs) and the fluid phase existing therein are fast diffusion pathways in rocks (e.g., Cole and Chakraborty, 2001; Watson, 1991). The curved GBs between neighboring grains having different sizes migrate under high temperature, resulting in grain growth. It has been reported that such grain boundary migration 
(GBM) enhances the isotopic equilibration between mineral grains and fluids.

Nakamura et al. (2005) experimentally investigated the oxygen isotope exchange process between a synthesized quartzite and an ${ }^{18} \mathrm{O}$-enriched aqueous fluid, and observed that the ${ }^{18} \mathrm{O}$ was enriched in the area swept by the GBs, which were rapidly equilibrated with the fluid. A similar enhancement of stable isotopic equilibration was reported for the ${ }^{40} \mathrm{Ca}-{ }^{44} \mathrm{Ca}$ exchange in calcite aggregates, in which GBM proceeded (McCaig et al. 2006). In the field of material science, it has been known that the diffusion of some specific elements into the GBs of polycrystalline metals cause their migration. This phenomenon, called chemically (or diffusion) induced grain boundary migration (CIGM, DIGM: e.g., Hillert and Purdy, 1978; Balluffi and Cahn, 1981), has also been found in carbonate systems (e.g., Evans et al. 1986). Nakamura et al. (2005) pointed out that the isotope-exchange enhancement that they found in grain-growing quartzite was a different process from CIGM (DIGM), in that the former was observed for grain growth driven by interfacial energy minimization and thus expected to occur in any deep-seated rocks, whereas the latter was driven by the lattice strain energy produced by the uptake of the elements specific to the crystals. CIGM (DIGM) often increases the interfacial energy, and thus is observed only in limited systems. Nakamura et al. (2005) differentiated the isotope exchange enhancements from CIGM and called the process as "grain boundary sweeping."

Given the mechanism of GB sweeping and the general occurrence of grain growth, GB sweeping is expected to be important for chemical equilibration, in addition to 
isotopic exchange. On the basis of the Damköhler number of a two phase flow, Nakamura et al. (2005) estimated the relative efficiency of GB sweeping and lattice diffusion in some element-mineral systems for which the data sets of the diffusion coefficient and grain growth rate were available. However, the enhancement of chemical exchange by GB sweeping has not been evaluated experimentally. Mishin and Razumovskii (1992) constructed a two-dimensional diffusion model for a moving GB and obtained analytical solutions for the concentration profiles as a function of diffusivity and GB velocity. In the present study, we carried out a series of experiments on the Ni diffusion in fluid-bearing, grain-growing forsterite aggregates (i.e., dunite) under the uppermost mantle conditions, and examined whether GB sweeping is a dominant mechanism for nickel uptake into olivine, as compared to lattice diffusion. We then analyzed the nickel concentration distribution in the run products by applying the analytical solution of Mishin and Razumovskii (1992) and obtained the diffusivity of nickel along the wet GBs and fluid networks in the fluid-bearing dunite.

CIGM and GB sweeping can be utilized to visualize the GBM, because the area in which chemical or isotopic exchange proceeded approximately corresponds to the area swept by the GBs when GBM is fast, as compared to the lattice diffusion. The velocity of GBM in polycrystalline metals has been estimated by measuring the width of the area in which the chemical exchange proceeded (e.g., Chongmo and Hillert 1982). By using the same method, Evans et al. (1986) evaluated the velocity of GBM in calcite bicrystals induced by Sr diffusion. Toriumi (1982) performed measurements of the 
velocity of GBM driven by the reduction of dislocation density in olivine aggregates and showed that the area swept by the GBs had a higher calcium concentration than the other areas. In-situ observations of GBM have been carried out by different methods for various systems, such as rock salt (Piazolo et al. 2006), metals (Ichinose and Ishida, 1989), and analogue materials (Ree and Park, 1997). In this study, we estimated the average GB velocity in dunites from the fraction of the area in which Ni-Mg exchange proceeded on the polished cross section of the run products. The estimated velocity of GBM was compared with that calculated from the grain size development.

\section{Theories and experimental design}

Mishin and Razumovskii (1992) developed a model for GB diffusion in a bicrystal system having a moving GB that is perpendicular to a diffusion surface (Fig. 1). Under the conditions of the inequalities (1a) and (1b), they obtained analytical solutions for the concentration profiles across the moving GB as Eqs. (1c-e):

$$
\begin{gathered}
\alpha=\frac{\delta}{2\left(D_{l} t\right)^{1 / 2}}<<1 \\
\beta=\frac{D^{\prime} \delta}{2 D_{l}\left(D_{l} t\right)^{1 / 2}}>>1 \\
C(\xi, w, \gamma)=\frac{2 C_{0}}{\pi^{1 / 2}} \exp \left(-\frac{\xi \gamma}{2}\right) \int_{0}^{\infty} \exp \left(-\theta^{2}\right) \cdot R\left(\frac{w^{2}}{8 \theta^{2}}+\frac{\xi}{2}, \gamma\right) \cdot d \theta
\end{gathered}
$$




$$
\begin{gathered}
R(p, q)=\frac{2}{\pi^{1 / 2}} \int_{0}^{\infty} \exp \left(-\frac{p^{2} q^{2}}{4 z^{2}}-z^{2}\right) \cdot d z \\
\xi=\frac{1}{2}\left(2 x+\left|x-\frac{\delta}{2}\right|-\left|x+\frac{\delta}{2}\right|\right)\left(D_{l} t\right)^{-1 / 2} ; w=\frac{y}{\left(D^{\prime} \delta\right)^{1 / 2}}\left(\frac{4 D_{l}}{t}\right)^{1 / 4} ; \gamma=\frac{V t}{\left(D_{l} t\right)^{1 / 2}}
\end{gathered}
$$

where $x, y, \delta$ and $V$ are the distance from the GB, the depth from the external surface from which the diffusant is supplied, the GB width and the GB velocity, respectively; $\xi$, $w$, and $\gamma$ are the non-dimensional parameters for the distance from the GB, the depth from the external surface, and the GB velocity, respectively. $D$ ' is the GB diffusion coefficient; $D_{l}$, the lattice diffusion coefficient; and $C_{0}$, the concentration at $y=0$. The inequalities (1a) and (1b) imply that GB diffusion is quasi-steady, and that the $y$ component of bulk diffusion is negligible as compared to the $x$ component, respectively (see Mishin and Razumovskii 1992 for detail). In the present experiments, both of them were satisfied (see Results for the values of $\alpha$ and $\beta$ in the experiments). We analyzed the experimental results on the basis of the solutions given by Eqs. (1c-e). It should be noted that the aqueous fluid phase was expected to be interconnected along the grain edges of the forsterite grains, because the measured dihedral angle of the aqueous fluid with two forsterite grains $\left(41^{\circ}\right.$; Ohuchi and Nakamura 2006) was lower than the threshold angle of the interconnection $\left(\sim 60^{\circ}\right)$. Therefore, the value of $D^{\prime} \delta$ calculated from the experimental results was not pure GB diffusivity, but included the diffusivity along the fluid network as well as the wet GBs.

The concentration profiles across a moving GB calculated from Eq. (1c) with 
different $\gamma$-values and a constant depth $(w=1)$, and those with different values of $w$ and a constant $\gamma$-value $(=3)$ are shown in Figs. $2 \mathrm{a}$ and $2 \mathrm{~b}$, respectively. As shown by Mishin and Razumovskii (1992), the length of the trail of diffusant concentration that is left behind the moving GB increases with an increase in $\gamma$. Figs. $2 \mathrm{a}$ and $2 \mathrm{~b}$ show that the area swept by the GB can be roughly approximated by the area in which the normalized concentration, $C^{*}=C(\xi, w, \gamma) / C(0, w, \gamma)$, is higher than the threshold concentration (in the normalized value), $C_{t h}$. The $C_{t h}$ can be assumed to be 0.6 in the case of $\gamma \geq 2$ and $w=$ $0.01-0.5$. The $C_{t h}=0.6$ case results in an overestimation of the area swept by the GBs for which $\gamma$ is small (e.g., $\gamma<2$ ), but this overestimation is small due to the limited diffusion distance.

In the model of Mishin and Razumovskii (1992), the partition coefficient of the diffusant between the crystal lattice and the GB (or the segregation factor) is assumed to be 1. If segregation of the elements (i.e., diffusant) into GBs occurs, the segregated elements may be trapped in the crystal lattice by fast GB migration and thus the area swept by GBs may be enriched with the elements (Watson 1996). This entrapment of segregated elements is effective when GB migration is sufficiently faster than diffusion of the element. Because the partition coefficient of nickel between the crystal lattice and the GB has been reported to be $\sim 1$ (Hiraga et al. 2003), we can properly apply the model of Mishin and Razumovskii (1992) to the nickel diffusion in forsterite aggregates.

We can estimate the average GB velocity in the sample, $v_{g b}$, by using the following equation: 


$$
v_{g b}=\frac{F \cdot \delta}{t_{a} \cdot \rho_{a}}
$$

where $F$ is the fraction of the area having a concentration higher than $C_{t h}$ in the analyzed area (i.e., the approximated area swept by GBs); $t_{a}$, annealing time; and $\rho_{a}$, average GB density (i.e., the volume fraction of GBs in the sample) during the annealing. The obtained values of $v_{g b}$ were evaluated in comparison with the average GB velocities calculated on the basis of the grain size measurements in the time series experiments.

\section{Experimental procedure}

\section{Sample preparation and diffusion experiments}

The starting material for the dunite was a gel powder having forsterite composition $\left(\mathrm{Mg}_{2} \mathrm{SiO}_{4}\right)$. The details of the sol-gel method used were described in Ohuchi and Nakamura (2006). All of the gel powder samples were dried in an oven at $300{ }^{\circ} \mathrm{C}$ for 12 $\mathrm{h}$ before the run to prevent the adsorption of moisture.

Diffusion experiments were conducted at $1200^{\circ} \mathrm{C}$ and $1.2 \mathrm{GPa}$ for $2-763 \mathrm{~h}$ using a Boyd-England type 3/4" piston-cylinder apparatus at Tohoku Univ. All of the runs were carried out under water-saturated (wet) conditions. The run conditions are summarized in Table 1. The appearance of a melt phase was not expected, because the melting temperature of forsterite under water-saturated conditions is much higher than the experimental temperature $\left(1410^{\circ} \mathrm{C}\right.$ at $2 \mathrm{GPa}$; Kushiro 1969).

An inner Ni-capsule that was coated with a $\mathrm{NiO}$ layer $(\sim 20 \mu \mathrm{m}$ thick $)$ was placed 
into a Pt-lined outer Ni-capsule, the starting materials were packed into the inner nickel capsule, and 1-2 wt.\% of distilled water was added using a microsyringe (Fig. 3). In an early stage of the experiments, we packed the starting materials directly into the Pt-lined $\mathrm{Ni}$-capsule without using the inner $\mathrm{Ni}-\mathrm{NiO}$ capsule to ensure that the grain size of the dunite attained a desirable size before the nickel penetrated into the sample through the platinum liner from the outer capsule. The drawback of this setup was that nickel concentration at the inner surface of the platinum liner increased during the run, thus the starting time and boundary condition (i.e., Ni concentration at the inner surface of the Pt liner) for the diffusion experiments were unclear. We later found that when the $\mathrm{Ni}-\mathrm{NiO}$ inner capsule was used, the nickel uptake into the dunite in the initial stage of grain growth was negligible, and we obtained better precision for the experimental results. This was probably because the initial grain growth of the dunite was very fast compared to the GB diffusion of nickel. Therefore, we reran all of the experiments with the $\mathrm{Ni}-\mathrm{NiO}$ inner capsule, except for a long-duration run (Per40-7). Another advantage of using the $\mathrm{Ni}-\mathrm{NiO}$ inner capsule was that it prevented the precipitation of $\mathrm{MgO}$ particles in the dunite, which occurred in the early experiments through a reduction reaction:

$$
\mathrm{Ni}{ }^{\text {in Pt-alloy }}+1 / 2 \mathrm{Mg}_{2} \mathrm{SiO}_{4}{ }^{\text {in olivine }}+\mathrm{H}_{2} \mathrm{O}=1 / 2 \mathrm{Ni}_{2} \mathrm{SiO}_{4}{ }^{\text {in olivine }}+\mathrm{MgO}+\mathrm{H}_{2}
$$

This reaction occurred because magnesium solubility in platinum is very low. In the experiments with the $\mathrm{Ni}-\mathrm{NiO}$ inner capsule, the $\mathrm{MgO}$ concentration in the $\mathrm{NiO}$ layer of the inner capsule increased through an exchange reaction with olivine:

$$
\mathrm{NiO}^{\text {inner capsule }}+1 / 2 \mathrm{Mg}_{2} \mathrm{SiO}_{4}{ }^{\text {in olivine }}=\mathrm{MgO}^{\text {inner capsule }}+1 / 2 \mathrm{Ni}_{2} \mathrm{SiO}_{4}{ }^{\text {in olivine }}
$$


An alloying reaction also proceeded at the interface between the Pt-liner and the inner capsule as follows:

$$
\mathrm{Pt}+\mathrm{NiO}^{\text {inner capsule }}=\mathrm{Pt}-\mathrm{Ni} \text { alloy }+1 / 2 \mathrm{O}_{2}
$$

This was, in contrast, an oxidation reaction that buffers the oxygen fugacity of the sample.

The pressure assembly used was a conventional NaCl-Pyrex cell. The temperature gradient along the Ni-Pt capsule was estimated to be $<5{ }^{\circ} \mathrm{C}$ at $1200{ }^{\circ} \mathrm{C}$ based on Nakamura and Watson (2001). The procedures for the high-pressure experiments were the same as described in Ohuchi and Nakamura (2006). The run products were recovered from the capsule assembly and cut with a low-speed saw. These were then impregnated with epoxy under a vacuum and polished using $1.0 \mu \mathrm{m}$ alumina powder followed by $0.06 \mu \mathrm{m}$ colloidal silica suspension. In order to precisely evaluate the spatial distribution of the GBs, grain sizes, and GB density, the GBs were etched using molten anhydrous borax (Ohuchi 2006).

\section{Microstructure characterization}

Back-scattered electron (BSE) images of the run products were obtained with a JEOL JSM-5410 scanning electron microscope at Tohoku University. Digitized BSE images of $1024 \times 736$ pixels were acquired at magnifications varying between $\times 75$ and $\times 3500$, depending on the grain size of the samples. Polished surfaces with relatively few plucked grains were selected for the BSE imaging. To obtain precise porosity values, the 
volume fractions of the pores were measured from BSE images of the non-etched surfaces of the polished samples. The BSE images were converted to a binary form leaving the pores, and their area was measured using image-processing software (Scion Image beta $3 b)$.

The diameters of circles having the same areas as the grains were measured using the software, and the mean grain size of forsterite was obtained. No correction for the sectioning effect was applied to the mean grain sizes in this study. Typically, 300-400 grains were measured in a sample. To obtain the GB density $(\rho)$, we first discriminated individual grains with the image processing software, and then measured the total length of the grain surface $\left(L_{g s}\right)$ in the unit area. The $\rho$ was then calculated using the relationship, $\rho=\delta \cdot L_{g s} / 2$, under the assumption of $\delta=1 \mathrm{~nm}$.

The misorientation angles between two neighboring grains and the spatial distribution of the GBs in some typical samples were evaluated by the indexation of the electron backscatterd diffraction (EBSD) using a JEOL JSM-6300 at Shizuoka University. The EBSD patterns were indexed using the CHANNEL+ software from HKL Technology (Schmidt and Olesen 1989). The EBSD pattern of each forsterite grain was obtained at $20 \mathrm{kV}$ acceleration voltage and $10 \mathrm{nA}$ probe current.

\section{Measurements of diffusion profiles, diffusivity, and volume fraction of Ni-rich region}

The concentration profiles and 8-bit element maps of nickel, magnesium, and silicon were measured using a JEOL JXA-8800 electron probe microanalyzer under the 
operating conditions of $15 \mathrm{kV}$ accelerating voltage and $30 \mathrm{nA}$ probe current. The relative statistical error of the quantitative analysis was less than $2 \%$. Elemental maps were acquired at $800-1024$ pixels in a side. Because the polished surfaces of the cylindrical samples are generally off-center, the depth of the analyzed positions from the interface with the capsule needed corrections. The depth from the interface with the capsule at an analyzed point on the polished surface was corrected by using the following equation:

$$
y=r-\left[r^{2}-R^{2}+(R-Y)^{2}\right]^{1 / 2}
$$

where $y$ is the corrected depth from the interface with the capsule; $r$, radius of the sample; $Y$, distance from the interface with the capsule on the polished surface (i.e., apparent depth); $R$, half width of the sample on the polished surface.

To obtain the lattice diffusion coefficient of the Ni-Mg interdiffusion in forsterite $\left(D_{l}\right)$, we used the nickel concentration profiles in a large forsterite grain $(\sim 100 \mu \mathrm{m}$ in diameter) in contact with the capsule. We treated the diffusion process as taking place in a semi-infinite plate, because the diffusion profiles were generally much shorter than the grain size. Accordingly, we calculated $D_{l}$ by fitting the following equation to the concentration profiles using a nonlinear least squares fitting method:

$$
\frac{C-C_{0}}{C_{i}-C_{0}}=\operatorname{erf}\left(\frac{y}{\left(4 D_{l} t\right)^{0.5}}\right)
$$

where $C$ is the nickel concentration at depth $y$ from the surface (at $y=0$ ); $C_{i}$, the infinite-distance concentration; and $C_{0}$, the concentration at the surface which was 
assumed to be constant.

The overall diffusivity of the nickel along the GBs and fluid networks was calculated for the concentration profiles away from the nickel source by using the following equation (McCaig et al. 2006, from Eq.(18) of Mishin and Razumovskii 1992):

$$
D^{\prime} \delta=\frac{V}{\left(d\left(\ln C / C_{0}\right) / d y\right)^{2}}
$$

Eq. (5) is practically applicable for a system in which $\gamma$ is higher than 6 . The $D^{\prime} \delta$ was estimated from the GB velocity $(V)$ and the average concentration gradient against the depth from the interface with the long side of the capsule (i.e., denominator of Eq. (5)). These profiles were obtained from the element maps of nickel (300-800 $\mu$ m width along the long side of the capsule) by averaging the X-ray counts (i.e., grayscale of pixels) at each depth in the map using the image software. Here, a linear relation between the X-ray counts and the nickel concentration was assumed. The obtained values of $D^{\prime} \delta$ were expected to be larger than the pure GB diffusivity in rocks in which the GBs are water saturated but no interconnected free-fluid phase is present.

The volume fractions of the Ni-rich region, in which the Ni-concentration was higher than the threshold concentration, $C_{t h}$, were obtained by measuring the fraction of the Ni-rich region on the polished surface. The 8-bit element maps of nickel were converted to a binary form distinguishing the area having a concentration higher than $C_{t h}(=0.6)$. The basis for this value is presented later in the results section. Here we 
assumed that the average Ni-concentration at the GBs (and thus $C_{t h}$ ) was constant and had a uniform value in the mapped area.

\section{Water content}

To determine the water content in the recovered samples, the unpolarized infrared absorption spectra of the polycrystalline samples were obtained from the doubly polished sections of the samples having $90-150 \mu \mathrm{m}$ thick. All of the measurements were carried out in air by putting the sections on a KBr plate and using a JASCO MFT-2000 Fourier-transform infrared spectrometer (FTIR). An aperture size of $50 \times 50 \mu \mathrm{m}^{2}$ was used for all of the measurements. The infrared spectra were taken from 4-5 points in each sample. The bulk water contents in the samples were determined by integrating the infrared absorption spectra from 3100 to $3700 \mathrm{~cm}^{-1}$ on the basis of the extinction coefficient calibration of Paterson (1982).

\section{Results}

\section{Porosity and water content}

Typical BSE images of the run products are shown in Fig. 4. No (Mg, Ni)O particle was observed in any of the run products. A layer of $(\mathrm{Mg}, \mathrm{Ni}) \mathrm{O}$ aggregate having $\sim 5 \mu \mathrm{m}$ thickness was formed between the platinum capsule and dunite in the product of run Per40-7, in which no Ni-NiO inner capsule was used. The pores in the run products were filled with aqueous fluid during the run. The volume fractions of the pore fluids 
(i.e., porosity) in the run products are summarized in Table 1. The samples had low $(0.2-1.1$ vol.\%) and high porosities (2.0-2.9 vol.\%), corresponding to the amount of added water to starting materials ( 2 and 3 wt.\% water, respectively). These values are lower than the porosities reported in a previous study (Ohuchi and Nakamura 2006, 2007b), which were closer to the porosity estimated from the densities of forsterite and fluid. This is because the fluid was preferentially distributed between the inner and platinum capsules, probably due to the good wettability of $\mathrm{NiO}$ to the aqueous fluid. A relatively high porosity (2.0 vol.\%) was obtained for the Per40-7 sample, in which the amount of added water was 1 wt.\%. This is consistent with the above assumption, since the Ni-NiO inner capsule was not used for Per40-7. The porosity of the dunite tends to decrease with the run duration. This is explained by the expulsion of pore fluid from the dunite to the interface with the capsule.

The average concentrations of water dissolved in the recovered dunite samples, as obtained by infrared spectroscopy, are summarized in Table 1. The infrared beam was strongly absorbed in the wavenumbers ranging from 3530 to $3650 \mathrm{~cm}^{-1}$. The average water contents in the dunite samples were found to be $248-756$ wt. ppm $\mathrm{H}_{2} \mathrm{O}$ and no systematic dependence on the amount of added water was observed. Since the reported water contents in olivine single-crystals under water-saturated conditions (135 wt. ppm $\mathrm{H}_{2} \mathrm{O}$ at $1100{ }^{\circ} \mathrm{C}$ and $2.5 \mathrm{GPa}$ : Kohlstedt et al. 1996; 115 wt. ppm $\mathrm{H}_{2} \mathrm{O}$ at $1300{ }^{\circ} \mathrm{C}$ and 2.0 GPa: Mosenfelder et al. 2006) are lower than our measurements despite their higher pressure conditions, the high water contents found in the present study are thought to 
have resulted from the water in the intergranular regions (Ohuchi and Nakamura 2007b).

\section{Grain growth}

The mean grain size and GB density of dunite are plotted as a function of the annealing time in Fig. 5. A continuous increase in the mean grain size and a continuous decrease in the GB density with the annealing time were observed in the dunites, showing the progress of normal grain growth. No abnormal grains of forsterite were observed in most of the samples, even though a 0.4 vol.\% of abnormal grains was observed in Per40-7. The slope of the best-fit line for the high porosity samples is clearly larger than that for the low porosity ones in Figs. 5a and 5b (hereafter, we define the low- and high-porosity samples as slow grain growth (SGG) and fast grain growth (FGG) samples, respectively). This suggests that the presence of a high volume fraction of fluids accelerated the grain growth. Although the porosity of Per40-7 sample is relatively high, its grain growth rate reported by Ohuchi and Nakamura (2007b) is slower than the others. We classified this sample as part of the SGG group.

The normal grain growth is expressed by the following equations:

$$
G^{n}-G_{h}^{n}=k t, G_{h}^{n}=G_{0}^{n}-k t_{0}
$$

where $n$ is the grain growth exponent; $k$, the growth rate constant, $G$, mean grain size; $G_{h}$, hypothetical initial grain size; $G_{0}$, the mean grain size at $t=t_{0}$ when NGG begins (e.g., Ohuchi and Nakamura 2007a). Considering the fact that $\rho$ is inversely 
proportional to the power-of- $G$ which depends on the grain packing, Eq. (6) can be converted into the following equation (for ease of calculation, $G>>G_{h}$ is assumed):

$$
\log \rho=A+B \cdot \log t
$$

where $A$ and $B$ are constants. We calculated the values of the constants in Eq. (6) $(n, k$, $\left.G_{h}\right)$ and Eq. (7) $(A, B)$ for forsterite in the run products using nonlinear and linear least squares fitting methods, respectively. The obtained values are summarized in Table 2. The values for Per40-7 were already reported in Ohuchi and Nakamura (2007b). The $n$-values of forsterite in the SGG and FGG samples are $6.4 \pm 0.6$ and $2.3 \pm 0.4$, respectively. The former value is similar to that reported for dunite under the same conditions (7.2 \pm 0.1 : Ohuchi and Nakamura 2007b), showing the good reproducibility of our experiments.

\section{Ni-concentration profiles}

Fig. 6 shows examples of the Ni-concentration profiles in large forsterite grains (i.e., abnormal grain with grain sizes of $\sim 100 \mu \mathrm{m}$ ) in direct contact with the capsule interface. The experimental result obtained without using the $\mathrm{Ni}-\mathrm{NiO}$ inner capsule (Per40-7) was used for the calculation of the $D_{l}$ of $\mathrm{Ni}-\mathrm{Mg}$, because the infiltration of nickel into the dunite was expected to begin after sufficient growth of abnormal forsterite grains (Ohuchi and Nakamura 2007b). The infinite-distance concentration of $\mathrm{NiO}$ was $\sim 0.3 \mathrm{wt} . \%$, resulting from infiltration of nickel into the dunite sample at the early stage of grain growth. We assumed that the $\mathrm{NiO}$ concentration at the interface with 
the capsule at $y=0$ was constant throughout the run. The profiles were well fitted by Eq. (4) and then the $D_{l}$ of Ni-Mg was obtained to be in the range of $1.3 \cdot 10^{-18}-4.2 \cdot 10^{-18} \mathrm{~m}^{2} / \mathrm{s}$ from the profiles. We use the average value $\left(2.4 \cdot 10^{-18} \mathrm{~m}^{2} / \mathrm{s}\right)$ as the $D_{l}$ of Ni-Mg under the experimental conditions.

Typical element maps of nickel in the SGG and FGG samples (Per87-1 and 88-1, respectively) are shown in Fig. 7. The average Ni-concentration profiles from the interface with the capsule are shown in Fig. 8. The average concentration smoothly decreases with the depth $y$. The inner areas of some grains away from the capsule have high Ni-concentrations (Fig. 7a). These grains are interpreted to have been cut near the polyhedral grain surface. The size of such grains in Fig.7a is relatively small compared to the surrounding grains, supporting this interpretation. The average $\mathrm{Ni}$-concentration increases with the annealing time. The $\mathrm{NiO}$ concentrations at the interface with the capsule at $y=0$ are almost constant throughout the runs (ca. $8 \mathrm{wt} . \%$ ), except for that without Ni-NiO inner capsule (Per40-7: Fig. 8b). This shows that olivine was equilibrated with the inner $\mathrm{Ni}-\mathrm{NiO}$ capsule. In the experiments without the $\mathrm{Ni}-\mathrm{NiO}$ inner capsule, the $\mathrm{NiO}$ concentration at the interface with the $\mathrm{Pt}(-\mathrm{Ni}$ alloy) liner was lower, even though the run duration was very long (Per40-7). This result justifies the constant boundary condition in the diffusion calculation.

The BSE images, element maps of nickel, and EBSD maps for coarse-grained SGG (Per40-7) and FGG (Per88-1) samples are shown in Fig. 9. The spatial distribution of the GBs enhanced by using the chemical etching technique (Figs. 9a and 9d) 
coincides with that identified by the EBSD mapping analysis (Figs. 9c and 9f). All of the GBs in Fig. 9, which can be distinguished in the BSE images, are enriched in nickel. The Ni-rich regions along the GBs are relatively thin in the SGG samples compared to the FGG ones. This difference may mostly be the result of the difference in the grain size. Many of the grain interiors in the FGG samples have Ni-rich regions with complex patterns, whereas the distributions of the Ni-rich regions are almost limited to near the present GBs in the SGG samples.

Fig. 10 shows various types of Ni-concentration profiles across the GBs in the SGG and FGG samples. Most of these profiles across the GBs show asymmetric patterns. The asymmetricity of the Ni-rich regions and shapes of the profiles found in the samples (Figs. 9 and 10) cannot be explained by the crystallographic anisotropy of cation diffusivity in olivine (factor $<8$ in the case of $\mathrm{Ni}$ diffusion at $1200{ }^{\circ} \mathrm{C}$ and $10^{-6}$ Pa: Petry et al. 2004), being consistent with the fact that most of the GBs migrated during the experiments. The relatively large forsterite grains tend to have thicker Ni-enriched margins. These characteristics are similar to those reported for the ${ }^{18} \mathrm{O}$-enrichment in quartzite experiments (Nakamura et al. 2005), showing that the GB sweeping proceeded for the Ni-dunite system. GBs generally migrate toward the concave direction, and the migration velocity is proportional to the curvature. In the run products, however, the relations between the asymmetricity of a Ni-rich region and the curvature of the GBs are not as clear as in the quartzite, especially in the FGG samples.

The Ni-concentration profiles can be divided into three types: those having a 
maximum Ni-concentration at the present GB (normal type; Fig. 10a), those having a maximum in the grain interior (reverse type; Fig. 10b), and those having more than two maxima (oscillatory type; Figs. 10c, d). The normal type dominates in the SGG samples, although the reverse type is subordinately found. Most of the profiles in the FGG samples were the oscillatory type. Most of the GBs in both the SGG and FGG samples have NiO concentrations $>1 \mathrm{wt} . \%$ at the depth $y<100 \mu \mathrm{m}$ (Figs. 9 and 10), although GBs with low $\mathrm{NiO}$ concentrations $(<0.2 \mathrm{wt} . \%)$ (LNGBs) were rarely found in any of the SGG samples. The volume fraction of the LNGBs in all of the GBs is typically $\sim 4 \%$. No LNGB was found in any of the FGG samples.

\section{Misorientation angles of GBs}

In order to examine the crystallographic properties of GBs in dunites, the frequency distributions of the misorientation angles of the GBs in the polished cross sections were examined (Fig. 11). The misorientation angles of the GBs in the SGG samples roughly follow the theoretical curve of a random distribution (Grimmer 1979), although they have two prominent maxima at $60^{\circ}$ and $80-95^{\circ}$. The presence of the first maximum at $60^{\circ}$ is a remarkable difference from the theoretical curve for the random distribution. This result is quite similar to that in partially molten olivine aggregates (Faul and Fitz Gerald 1999). The misorientation angles of the GBs in the FGG samples follow the theoretical curve of a random distribution. The frequency of the low-angle GBs with misorientation angles of $<15^{\circ}$ is less than $1 \%$ in all of the samples. 


\section{Diffusivity of nickel along the GBs and fluid networks}

In order to calculate the diffusivity of nickel along the wet GBs and fluid networks $\left(D^{\prime} \delta\right)$, we evaluated the $\gamma$-value of each samples from the grain growth data. We can calculate the average GB velocity, $V_{g b}$ by substituting the values of $n$ and $k$ into the following equation:

$$
V_{g b}=\frac{1}{t_{2}-t_{1}} \int_{t 1}^{t 2} \frac{\partial G(t)}{\partial t} \cdot d t
$$

where $t_{1}$ and $t_{2}$ represent time $\left(t_{2}>t_{1} \geq t_{0}\right)$, and $G(t)$ is the mean grain size at time $t$ expressed as Eq. (6). The expression $t_{1}=t_{0}=0$ was assumed and $t_{a}$ was substituted into $t_{2}$, for the calculation of $V_{g b}$. The $\gamma$-values calculated from Eqs. (1e) and (8) are shown in Table 3 and plotted against the annealing time in Fig. 12. All of the $\gamma$-values are higher than 1, showing that an increase in the Ni-concentration in the dunites is dominated by GBM, as predicted by Nakamura et al. (2005). Assuming $G>>G_{h}$, Eq. (6) is approximated as $G^{n}=k t$ and then $\gamma$ is expressed by the following equation:

$$
\gamma \approx \frac{k^{1 / n}}{n \cdot D_{l}^{1 / 2}} \cdot t^{(2-n) / 2 n}
$$

This equation shows that $\gamma$ can increase and decrease with time in the case of $n<2$ and

$>2$, respectively. The time dependency of $\gamma$ for the SGG samples, which decrease with increase in the annealing time, satisfies the relation of Eq. (9) well (Fig. 12). Although the $n$-value of the FGG samples is 2.3 , the $\gamma$-values of the FGG samples increase with 
the annealing time. This discrepancy could have been caused by the fact that the assumption of $G>>G_{h}$ is not applicable to the FGG samples with relatively short annealing durations $\left(G_{h}=16.3 \mu \mathrm{m} ; G=25.9-40.8 \mu \mathrm{m}\right)$. All of the SGG samples except for Per40-7 $(G \leq 43.9 \mu \mathrm{m})$ and all of the FGG samples $(G \leq 63.2 \mu \mathrm{m}$; Per78-1, 88-1, 90-1) have $\gamma$-values higher than 6. Fig. 13 shows the normalized Ni-concentration profiles of these samples. We obtained the average values of $D^{\prime} \delta$ by substituting the values of $d(\ln C) / d y$ and $V_{g \mathrm{~b}}$ into Eq. (5) to be $6.5 \cdot 10^{-19}$ and $6.7 \cdot 10^{-18} \mathrm{~m}^{3} / \mathrm{s}$ for the SGG and FGG samples, respectively (Table 3). The non-dimensional depth from the sample surface, $w$, was then calculated to be in the range of 0.01 to 5 under the experimental conditions by substituting the experimentally obtained values of $D_{l}$ and $D^{\prime} \delta$ into Eq. (1e). The nondimensional parameters in the inequalities (la-b) were obtained to be $\alpha=$ $2.0 \cdot 10^{-4}-3.8 \cdot 10^{-3}$ and $\beta=5.3 \cdot 10^{4}-1.1 \cdot 10^{7}$ under the experimental conditions (in the case of $\delta=1 \mathrm{~nm}$ ), showing that the assumptions in the inequalities (1a-b) are fulfilled.

The average $\mathrm{NiO}$ concentration in the area between the depth $y=20$ and 700 (in $\mu \mathrm{m}), C_{20-700}$, is plotted against the GBM distance during the annealing, $V_{g b} \cdot t_{a}$, and against the $\gamma$-values in Figs. $14 \mathrm{a}$ and $14 \mathrm{~b}$, respectively. $C_{20-700}$ represents the bulk flux from the nickel source into the dunite via diffusion along the GBs and the fluid networks. In order to exclude the effect of lattice diffusion from the interface with the capsule, the depths of less than $20 \mu \mathrm{m}$ were excluded from the measurements. The depth $y=700 \mu \mathrm{m}$ roughly corresponds to the center of the recovered samples. The increase of $C_{20-700}$ with $V_{g b} \cdot t_{a}$ shows that the GBM enhanced the flux from the Ni-source. 
The $C_{20-700}$ in the SGG samples gradually decreases with an increase in the $\gamma$-values from 12.7. This shows that the GB velocity was too fast for the GBs to be equilibrated with the inner $\mathrm{Ni}-\mathrm{NiO}$ capsule when $\gamma>12.7$. This is consistent with the observation that the nickel uptake into forsterite grains was negligible during the initial sintering from the powdered starting material. This is also consistent with the result that the slope $C_{20-700} / V_{g b} \cdot t_{a}$ of the FGG samples is smaller than (about $2 / 3$ of) that of the SGG ones in Fig. 14a.

\section{Average GB velocity estimated from the volume fractions of $\mathrm{Ni}$-rich region}

The profiles of the volume fractions of $\mathrm{Ni}$-rich regions from the interface with the capsule are shown in Fig. 15. The volume fraction increases with the annealing time and decreases with an increase in the depth $y$. In the long duration experiments (Per40-7: $763 \mathrm{~h}$ ), the heterogeneity of the nickel concentration due to the large grain size is not fully averaged in the maps, causing a zigzag pattern in the profiles. We estimated the average GB velocity, $v_{g b}$, by substituting $\rho_{a}$ and the average volume fraction of the Ni-rich region in the analyzed area $\left(F_{a-b}\right)$ into Eq. (2), where $a$ and $b$ represent the minimum and maximum depths (in $\mu \mathrm{m}$ ) from the interface with the capsule in the analyzed area, respectively. We used the value $C_{t h}=0.6$ for the measurement of $F_{a-b}$, because all of the samples have $\gamma$-values $>2$ and the normalized depth $(w)$ is larger than 0.01 under the experimental conditions. In order to exclude the effect of the lattice diffusion of cations from the interface with the capsule in the increase of $F$, a fixed 
value of $a=20 \mu \mathrm{m}$ was used for all of the measurements. The value of $b$ was determined so that $w$ was in the range of $0.01-0.5$ in the analyzed area, since the area swept by the GBs could be accurately obtained by using $C_{t h}=0.6$ under the condition of $\gamma>2$ (Figs. 2a and 2b). The $\rho_{a}$ was calculated by substituting the values of $A$ and $B$ into Eq. (7). The parameters used and the results of the calculation are summarized in Table 3.

The $v_{g b}$ and $v_{g b} / V_{g b}$ values are plotted against $V_{g b}$ in Fig. 16. The $v_{g b}$ values show good agreement with those of $V_{g b}$ on the logarithmic scale in the wide range. The $v_{g b} / V_{g b}$ ratios of the SGG samples are within the range of $0.8-1.6$, showing that $v_{g b}$ is roughly coincident with $V_{g b}$ on the linear scale. These results strongly support the conclusion that the Ni-rich regions of the samples correspond to the areas swept by GBs that have high Ni-concentrations (i.e., $\geq C_{t h}$ ) in the SGG samples. The $v_{g b} / V_{g b}$ ratios of the FGG samples are considerably smaller than those of the SGG ones $(0.3-0.6)$. This suggests that the $F_{a-b}$ was underestimated, being consistent with the dominant appearance of the oscillatory-type Ni-concentration profiles in the FGG samples.

\section{Discussion}

\section{Evaluation of the effect of GBM on the Ni-Mg exchange}

In order to evaluate the effect of GBM on the Ni-Mg exchange between the dunite and the $\mathrm{NiO}$ source, we calculated the average $\mathrm{NiO}$ concentration in a system with only stationary GBs using the following equation for a bicrystal system (e.g., Fisher 1951): 


$$
C_{a-b}^{\prime}=C_{0} \cdot \int_{a}^{b}\left(\int_{0}^{L / 2} \exp \left(-\frac{\pi^{-1 / 4} y}{\left(D^{\prime} \delta\right)^{1 / 2}}\left(\frac{4 D_{l}}{t}\right)^{1 / 4}\right) \operatorname{erfc}\left(\frac{x}{2}\left(D_{l} t\right)^{-1 / 2}\right) \cdot d x\right) \cdot d y
$$

where $L$ is the average distance between the neighboring GBs, and $x$, distance from a GB $(0 \leq \mathrm{x} \leq L)$. The relation $L=0.644 G$, which can be obtained with the assumption that each grain has a uniform size and a regular hexagonal shape, was used for the calculation of Eq. (10).

The ratio $C_{20-700} / C^{\prime}{ }_{20-700}$ is plotted against the annealing time and $\gamma$ in Figs. $17 \mathrm{a}$ and $17 \mathrm{~b}$, respectively. The ratios are in the range of $1.5-80.1$, showing that all of the samples have higher nickel concentrations than that calculated from Eq. (10). The $C_{20-700} / C^{\prime}{ }_{20-700}$ ratios decrease with the annealing time and increase with $\gamma$. These results show that the decrease in the GB velocity with the annealing time causes a decrease in the ratio $C_{20-700} / C^{\prime}{ }_{20-700}$, namely, the effect of GBM on the chemical exchange decreases with an increase in the mean grain size.

\section{Concentration profiles across the GBs and GB diffusivity}

The theoretical concentration profiles across the GBs have a maximum concentration at the GBs (Fig. 2; Mishin and Razumovskii 1992). Nakamura et al. (2005) reported the normal type of concentration profiles for ${ }^{18} \mathrm{O}$ in quartzite. Most of the grains in the SGG samples in the present experiments are of this type (Fig. 10a). By contrast, some of the Ni-concentration profiles in the FGG samples have maximum concentrations in the interior of the grains and decrease toward the GBs (reverse type; 
Fig. 10b) or have more than two maxima (oscillatory type; Figs. 10c and 10d). These types of profiles are also reported by McCaig et al. (2006) for ${ }^{44} \mathrm{Ca}$ in calcite. In Fig. 1 of Nakamura et al (2005), it is also observed that some large grains have maximum cathodoluminescence intensities and ${ }^{18} \mathrm{O}$ concentrations in their interiors near the margin.

The repeated sweeping by GBs, including the complete consumption of small grains, could have created the complex Ni distribution patterns. However, the reverse and oscillatory type profiles appear preferentially in the FGG samples, even in the relatively fine-grained ones, but not in the coarse-grained SGG samples. This observation suggests that the dominant factor responsible for the complex profiles is not the repeated GB sweeping but resides in the characteristics of the GBs in the FGG samples. In the two-dimensional diffusion, the concentration profile across a GB should become the normal type if the supply of diffusant into the GB via GB diffusion and the leakage from the GB into the crystal interior via lattice diffusion are constant. On the condition that the two fluxes are comparable, the concentrations at the migrating GBs may decrease when $\gamma$ (i.e., GB velocity) increases or $D^{\prime} \delta$ decreases, and then the reverse type profile may be formed. If the values of $\gamma$ or $D^{\prime} \delta$ oscillate, the oscillatory type may be formed. The grain edges of the FGG (high water content) samples are mostly wet by the pore fluid, while fluid-free triple junctions are common in the SGG samples (Figs. 4, $7,9,10)$. The pinning of GBM by the fluids and GB-pore separation would have caused the oscillation of the GB velocity (Hsueh et al. 1982). These processes should have also 
changed the geometry of the fluid network during the grain growth, leading to the oscillation of the local $D^{\prime} \delta$.

\section{Comparison of the diffusion data}

The Ni-Mg interdiffusion coefficients in olivine, which have been studied under various experimental conditions (e.g., Morioka 1981), are generally much higher than the self diffusion of oxygen and silicon. Using the pre-exponential parameter $\left(2.2 \cdot 10^{2}\right.$ $\left.\mathrm{cm}^{2} / \mathrm{s}\right)$ and the activation energy $(414 \mathrm{~kJ} / \mathrm{mol})$ for Ni-Mg interdiffusion along the $c$ axis reported by Morioka (1981) and the apparent activation volume for Ni tracer diffusion along the $c$ axis $\left(5.4-7.0 \mathrm{~cm}^{3} / \mathrm{mol}\right)$ reported by Holzapfel et al. (2007), the Ni-Mg interdiffusion coefficient at $1200{ }^{\circ} \mathrm{C}$ and $1.2 \mathrm{MPa}$ under dry conditions is estimated to be in the range of $9.4 \cdot 10^{-18}-1.1 \cdot 10^{-17} \mathrm{~m}^{2} / \mathrm{s}$. The estimated value is $4-5$ times larger than the Ni-Mg interdiffusion coefficient obtained in this study $\left(2.4 \cdot 10^{-18} \mathrm{~m}^{2} / \mathrm{s}\right)$. This discrepancy would results from the dependency of Ni-diffusivity on the crystallographic orientations (Ni-diffusivity along the $c$-axis is a factor of 8 times faster than that along $a$ - and $b$-axes at $1200^{\circ} \mathrm{C}$ and $10^{-6} \mathrm{~Pa}$ : Petry et al. 2004), Although the effect of water on the Ni-Mg interdiffusion coefficient is not considered, the effect would be small because the effect of water on the Fe-Mg interdiffusion is estimated to be relatively small at high pressures (e.g., factor $\sim 2$ at $1200{ }^{\circ} \mathrm{C}$ and $2 \mathrm{GPa}$ : Costa and Chakraborty 2008).

The $D^{\prime} \delta$ of magnesium in a forsterite aggregate at $1200^{\circ} \mathrm{C}$ and $0.1 \mathrm{GPa}$ under dry conditions has been reported to be $3.2 \cdot 10^{-23} \mathrm{~m}^{3} / \mathrm{s}$ (Farver et al. 1994). No report is 
available for the GB diffusivity of nickel. The GB diffusivity of magnesium at $1200{ }^{\circ} \mathrm{C}$ and $1.2 \mathrm{GPa}$ is expected to be similar to this value, because an apparent activation volume for the GB diffusivity of magnesium is $\sim 1 \mathrm{~cm}^{3} / \mathrm{mol}$ (Farver et al. 1994). Therefore, the overall diffusivity of nickel along the wet GBs and fluid networks under water-saturated condition is estimated to be $10^{4}-10^{5}$ times larger than that of magnesium under dry conditions at $1200{ }^{\circ} \mathrm{C}$ and $1.2 \mathrm{GPa}$. Considering that the GB diffusivity of magnesium under wet conditions is only about 5 times that under dry conditions (Farver et al. 1994; Yund 1997), this large $\left(10^{4}-10^{5}\right)$ difference is attributed to fast diffusion via an interconnected aqueous fluid phase. Watson (1991) conducted diffusion experiments on fluid bearing dunites and reported the bulk diffusivity of iron in the intergranular aqueous fluid as $10^{-12}-10^{-13} \mathrm{~m}^{2} / \mathrm{s}$ at $1 \mathrm{GPa}$ and $1200^{\circ} \mathrm{C}$. Assuming that the thickness of intergranular fluid layers is in the range of $10 \mathrm{~nm}$ to $1 \mu \mathrm{m}$ (e.g., Cmíral et al. 1998), the $D^{\prime} \delta$ of iron in olivine aggregates is expected to be $10^{-18}-10^{-21} \mathrm{~m}^{3} / \mathrm{s}$ at $1 \mathrm{GPa}$ and $1200^{\circ} \mathrm{C}$. This is roughly consistent with the $D^{\prime} \delta$ of nickel obtained in the present experiments. Contrary to this coincidence, the diffusivity of silicon in aqueous fluid has been reported to be $\sim 4 \cdot 10^{-7} \mathrm{~m}^{2} / \mathrm{s}$ at $1 \mathrm{GPa}$ and $1200^{\circ} \mathrm{C}$ (Watson and Wark 1997), being much larger than the diffusivity of iron and nickel along intergranular aqueous fluid. This discrepancy can be attributed to the effect of unwetted grain edges and GBs on the eradication of long-range fluid interconnectivity. Despite dihedral angle between mineral and fluid is less than the threshold angle of ca. $60^{\circ}$ under the experimental conditions, the bulk diffusivity of chlorine in fluid-bearing quartzites was drastically 
decreased (4 orders of magnitude) with increase of unwetted grain edges and GBs (Brenan 1993).

\section{Effects of grain growth on chemical homogenization in the upper mantle}

The importance of grain growth and dynamic recrystallization in the mantle rheology has been widely recognized. These processes, accompanied by GBM, are also important for chemical homogenization in rocks, because the efficiency of GB diffusion in bulk-rock diffusivity is controlled by the grain size. Nakamura et al. (2005) proposed a model to evaluate the relative efficiency between grain growth and lattice diffusion in the chemical exchange between aqueous fluids and rocks on the basis of the Damköhler number, which is a dimensionless parameter describing the rate of a reaction relative to the rate of fluid flow in a reactive transport system. The relative efficiency changes according to the grain growth exponent $n$ and the grain size, since the GB velocity is strongly dependent on these two parameters. Here we make a similar but more direct comparison of the two elementary processes by formulating the time dependency of $\gamma$, which is a fundamental factor for determining the efficiency of the GBM in the chemical exchange in rocks.

The $\gamma$ is expressed as a function of $G$ by substituting Eq. (6) into Eq. (9) with the assumption of $G \gg>G_{h}$ :

$$
\gamma \approx \frac{k^{1 / 2}}{2 n \cdot D_{l}^{1 / 2}} \cdot G^{(2-n) / 2}
$$


This equation shows that the time (i.e., grain size) dependency of $\gamma$ is a function of $n$. The $\gamma$ increases and decreases with time in the case of $n<2$ and $>2$, respectively. This is consistent with the result of the formulation in Nakamura et al. (2005). Since $n$-values have been reported to be in the range of 2 to 11 for various monomineralic (e.g., Tullis and Yund 1982) and bimineralic rocks (e.g., Yamazaki et al. 1996), $\gamma$ is almost constant or decreases with the progress of grain growth. Eq. (11) also shows that $\gamma$ is larger in a case where the lattice diffusion coefficient is smaller.

Fig. 18 shows the relationships between $\gamma$ and the mean grain size of forsterite in dunites and wehrlites (i.e., forsterite-diopside bimineralic rocks) as calculated by Eq. (11) for Ni-Mg interdiffusion at $1200^{\circ} \mathrm{C}$ and $1.2 \mathrm{GPa}$ under dry and water-saturated conditions (Morioka 1981; this study) (Fig. 18a), and for the oxygen and silicon self-diffusion (Dohmen et al. 2002) at $1200{ }^{\circ} \mathrm{C}$ and $1.2 \mathrm{GPa}$ under dry conditions (Fig. 18b). Typical grain sizes of olivine in natural peridotites (micrometer to centimeter order) were considered for the calculation. Chemical exchange is enhanced by GBM in the case of $\gamma>1$ (Fig. 2). The calculation was made by substituting into Eq. (11) the values of $n$ and $k$ for dunites and wehrlites at $1200^{\circ} \mathrm{C}$ and $1.2 \mathrm{GPa}$ under dry (Ohuchi and Nakamura 2007a) and water-saturated conditions (dunite: this study; wehrlites: Ohuchi and Nakamura 2007b). The $n$ and $k$ values used for the calculations are summarized in Table 4.

The $\gamma$-values for the Ni-Mg interdiffusion under the dry and wet conditions are higher than 1 in the case of fine-grained dunite $(G<100 \mu \mathrm{m})$, although they are mostly 
lower than 1 in the case of wehrlites because of their small values of $k$ (Fig. 18). These results suggest that the degree of chemical exchange between rocks and fluids would be different between the monomineralic and polymineralic domains even if they are to interact with the same fluid, since the former generally has a much larger grain growth rate than the latter (Ohuchi and Nakamura 2007a, b).

The preferential progress of chemical exchange is expected in finer grained rocks (e.g., shear zone) compared to coarser rocks (Fig. 18). This result supports the interpretation of the texture-geochemistry relationships found in the peridotite xenolith (Xu et al. 1998) that chemical alteration of protogranular peridotites can be attributed to recrystallization enhanced by fluid infiltration. Such a selective metasomatism

(lithological dependence of the alteration degree) would be explained by taking the GB sweeping process into consideration.

The $\gamma$-values for oxygen and silicon self-diffusion in the dry condition are higher than 1 in a wide range of mean grain sizes (up to the centimeter order), suggesting that GBM enhances the chemical homogenization of oxygen and silicon isotopes and other slow-diffusion species in a widespread area of the dry upper mantle. Therefore, grain growth rate (i.e., $n$ and $k$ ) is a fundamental and important parameter for evaluating the time-scale of chemical homogenization in the upper mantle.

\section{Conclusions}

1. Effective enrichment of nickel by GB sweeping proceeded in synthesized dunite 
with a Ni-rich aqueous fluid system. The average nickel concentration in the dunites, of which the mean grain size ranged from 20.8 to $63.2 \mu \mathrm{m}$, increased to be $1.5-80.1$ times higher than that in the system with stationary GBs.

2. The $v_{g b} / V_{g b}$ ratios ( $v_{g b}$ : average GB velocity estimated from the volume fraction of the Ni-rich region; $V_{g b}$ : average GB velocity calculated on the basis of the grain growth exponent and the growth rate constant) of the SGG samples were in the range of 0.8-1.6, showing that $v_{g b}$ was roughly coincident with $V_{g b}$. This confirms that the Ni-rich regions in the dunites correspond to the areas swept by the GBs with Ni-concentrations higher than the threshold value, $C_{t h}$.

3. The overall diffusivities of nickel along the wet GBs and fluid networks, $D^{\prime} \delta$, was found to be $6.5 \cdot 10^{-19}$ and $6.7 \cdot 10^{-18} \mathrm{~m}^{3} / \mathrm{s}$ for the SGG and FGG samples, respectively. These values are $10^{4}-10^{5}$ times higher than the GB diffusivity of magnesium under dry conditions at $1200{ }^{\circ} \mathrm{C}$ and $1.2 \mathrm{GPa}$ (Farver et al. 1994; Yund 1997). This difference is mostly attributed to the fast diffusion via an interconnected aqueous fluid phase.

4. Our experimental results suggest that the degree of chemical exchange between rocks and fluids may be different between the monomineralic and polymineralic domains, which have relatively fast and slow grain growth rates, respectively.

5. The experimental results suggest that the GBM enhances chemical homogenization, particularly that of slow-diffusion species in the upper mantle such as silicon and oxygen. The grain growth rate is an important factor for evaluating the time-scale of chemical homogenization in the upper mantle. 


\section{Acknowledgments}

T.O. carried out the experiments and interpretation of the results. M.N. contributed to the theoretical calculations and discussion, and K.M. contributed to the EBSD analysis. We thank R. Dohmen and T. Hiraga for their critical reviews. This work was financially supported by the JSPS Postdoctoral Fellowship for Research Abroad awarded to T.O., a Grant-in-Aid for Scientific Research to M.N., the Global COE program of Ehime University, and the 21 st century COE and the Global COE programs of Tohoku University. 


\section{References}

Balluffi RW, Cahn JW (1981) Mechanism for diffusion induced grain boundary migration. Acta Metall 29: 493-500

Brenan JM (1993) Diffusion of chlorine in fluid-bearing quartzite: effects of fluid composition and total porosity. Contrib Mineral Petrol 115: 215-224

Chongmo L, Hillart M (1982) Diffusion induced grain boundary migration in Cu-Zn. Acta Metall 30: 1133-1145

Cmíral M, Fitz Gerald JD, Faul UH, Green DH (1998) A close look at dihedral angles and melt geometry in olivine-basalt aggregates: a TEM study. Contrib Mineral Petrol 130: $336-345$

Cole DR and Chakraborty S (2001) Rates and mechanisms of isotope exchange. In: JW Valley and DR Cole (ed) Stable Isotope geochemistry, Reviews in Mineralogy, vol. 43, Mineralogical Society of America, 83-233.

Costa F, Chakraborty S (2008) The effect of water on Si and O diffusion rates in olivine and implications for transport properties and processes in the upper mantle. Phys Earth Planet Inter 166: 11-29.

Dohmen R, Chakraborty S, Becker H-W (2002) Si and O diffusion in olivine and implications for characterizing plastic flow in the mantle. Gephys Res Lett 29: 2030, doi: 10.1029/2002GL015480

Evans B, Hay RS, Shimizu N (1986) Diffusion-induced grain boundary migration in calcite. Geology 14: 60-63 
Farver JR, Yund RA, Rubie DC (1994) Magnesium grain boundary diffusion in forsterite aggregates at $1000^{\circ}-1300^{\circ}$ and $0.1 \mathrm{MPa}$ to $10 \mathrm{GPa}$. J Geophys Res 99 : 19809-19819

Faul UH, Fitz Gerald JD (1999) Grain misorientations in partially molten olivine aggregates: an electron backscatter diffraction study. Phys Chem Minerals 26: $187-197$

Fisher JC (1951) Calculation of diffusion penetration curves for surface and grain boundary diffusion. J Appl Phys 22: 74-77

Grant KJ, Kohn SC, Brooker RA (2006) Solubility and partitioning of water in synthetic forsterite and enstatite in the system $\mathrm{MgO}-\mathrm{SiO}_{2}-\mathrm{H}_{2} \mathrm{O} \pm \mathrm{Al}_{2} \mathrm{O}_{3}$. Contrib Mineral Petrol 151: 651-664

Grimmer H (1979) The distribution of disorientation angles if all relative orientations of neighbouring grains are equally probable. Scr Metall 13: 161-164

Hillert M, Purdy GR (1978) Chemically induced grain boundary migration. Acta Metall 26: $333-340$

Hiraga T, Anderson IM, Kohlstedt DL (2003) Chemistry of grain boundaries in mantle rocks. Am Mineral 88: 1015-1019

Holzapfel C, Chakraborty S, Rubie DC, Frost DJ (2007) Effect of pressure on Fe-Mg, $\mathrm{Ni}$ and $\mathrm{Mn}$ diffusion in $\left(\mathrm{Fe}_{\mathrm{x}} \mathrm{Mg}_{1-\mathrm{x}}\right)_{2} \mathrm{SiO}_{4}$ olivine. Phys Earth Planet Inter 162: $186-198$

Hsueh CH, Evans AG, Coble RL (1982) Microstructure development during 
final/intermediate stage sintering- I: pore/grain boundary separation. Acta Metal 30: $1269-1279$

Ichinose H, Ishida Y (1989) High-resolution in situ observation of moving grain boundaries in gold by high-resolution electron microscopy. Philosophical Magazine A 60: $555-562$

Kohlstedt DL, Keppler H, Rubie DC (1996) Solubility of water in the $\alpha, \beta$ and $\gamma$ phases of $(\mathrm{Mg}, \mathrm{Fe})_{2} \mathrm{SiO}_{4}$. Contrib Mineral Petrol 123: 345-357

McCaig A, Covey-Crump SJ, Ismail WB, Lloyd GE (2006) Fast diffusion along mobile grain boundaries in calcite. Contrib Mineral Petrol 153: 159-175

Mishin YM, Razumovskii IM (1992) A model for diffusion along a moving grain boundary. Acta Metall Mater 40: 839-845

Morioka M (1981) Cation diffusion in olivine-II. Ni-Mg, Mn-Mg, Mg and Ca. Geochm Cosmochim Acta 45: 1573-1580

Mosenfelder JL, Deligne NI, Asimow PD, Rossman GR (2006) Hydrogen incorporation in olivine from 2-12 GPa. Am Mineral 91: 285-294

Nakamura M, Watson EB (2001) Experimental study of aqueous fluid infiltration into quartzite: implications for the kinetics of fluid redistribution and grain growth driven by interfacial energy reduction. Geofluids 1: 73-89

Nakamura M, Yurimoto H, Watson EB (2005) Grain growth control of isotope exchange between rocks and fluids. Geology 33: 829-832

Ohuchi T (2006) A new chemical etching technique for peridotites using molten 
anhydrous borax. Am Mineral 91: 579-583

Ohuchi T, Nakamura M (2006). Microstructure evolution of aqueous fluid-bearing wehrlites: implications for the fluid distribution in polymineralic rocks. J Geophys Res 111: 10.1029/2004JB003340

Ohuchi T, Nakamura M (2007a) Grain growth in forsterite-diopside system. Phys Earth Planet Inter 160: 1-21

Ohuchi T, Nakamura M (2007b) Grain growth in the system forsterite-diopside-water. Phys Earth Planet Inter 161: 281-304

Paterson MS (1982) The determination of hydroxyl by infrared absorption in quartz, silicate glasses and similar materials. Bull Minéral 105: 20-29

Petry C, Chakraborty S, Palme H (2004) Experimental determination of Ni diffusion coefficients in olivine and their dependence on temperature, composition, oxygen fugacity, and crystallographic orientation. Geochim Cosmochim Acta 68: $4179-4188$

Pizaolo S, Bestmann M, Prior DJ, Spiers CJ (2006) Temperature dependent grain boundary migration in deformed-then-annealed material: Observations from experimentally deformed synthetic rocksalt. Tectonophys 427: 55-71

Ree J-H, Park Y (1997) Static recovery and recrystallization microstructures in sheared octachloropropane. Jour Struct Geol 19: 1521-1526

Schmidt NH, Olesen NO (1989) Computer-aided determination of crystal lattice orientation from electron channeling patterns in the SEM. Can Mineral 27: 15-22 
Toriumi M (1982) Grain boundary migration in olivine at atmospheric pressure. Phys Earth Planet Inter 30: 26-35

Tullis J, Yund RA (1982) Grain growth kinetics of quartz and calcite aggregate. Jour Geol 90: 301-31

Watson EB (1991) Diffusion in fluid-bearing and slightly-melted rocks: experimental and numerical approaches illustrated by iron transport in dunite. Contrib Mineral Petrol 107: 417-434

Watson EB (1996) Surface enrichment and trace-element uptake during crystal growth. Geochim Cosmochim Acta 60: 5013-5020.

Watson EB, Eark DA (1997) Diffusion of dissolved $\mathrm{SiO}_{2}$ in $\mathrm{H}_{2} \mathrm{O}$ at $1 \mathrm{GPa}$, with implications for mass transport in the crust and upper mantle. Contrib Mineral Petrol 130: 66-80

Xu Y, Menzzies MA, Vroon P, Mercier JC, Lin C (2005)

Texture-temperature-geochemistry relationships in the upper mantle as revealed from spinel peridotite xenoliths from Wangqing, NE China. J Petrol 39: 469-493

Yund RA (1997) Rates of grain boundary diffusion through enstatite and forsterite reaction rims. Contrib Mineral Petrol 126: 224-236

Yamazaki D, Kato T, Ohtani E, Toriumi M (1996) Grain growth rate of $\mathrm{MgSiO}_{3}$-perovskite and periclase under lower mantle conditions. Science 274: $2052-2054$ 


\section{Figure captions}

Fig. 1. The coordinate system for the two-dimensional diffusion model of Mishin and Razumovskii (1992). The large black arrow and small arrows represent the direction of GB diffusion and lattice diffusion from the GB, respectively. The large white arrow shows the direction of GBM.

Fig. 2. (a) Theoretical concentration profiles across moving GBs having various non-dimensional GB velocity $\gamma$ at a non-dimensional depth $w=1$, and (b) those having $\gamma$ $=2$ at various $w$. The assumptions of $\alpha<<1$ and $\beta>>1$ were made for the calculation. The position of the present GB in each profile accords with its peak position. The dot-dashed line in Fig. 2a represents the position of the GBs at $t=0$.

Fig. 3. (a) The design of Pt-lined Ni-capsule with an inner Ni-NiO capsule. (b) A schematic representation of the nickel and magnesium transport between the dunite sample and the NiO-layer (surface of the inner Ni-capsule) via GBs and interconnected aqueous fluid phase along the grain edges and corners (large arrows). The Ni-Mg exchange proceeds between the NiO-layer and forsterite. The lattice interdiffusion of $\mathrm{Ni}-\mathrm{Mg}$ (small arrows) is limited near the GBs and the interface with the NiO-layer.

Fig. 4. The representative back scattered electron (BSE) images of the dunite having (a) low (0.2-1.1 vol.\%) (Per87-1) and (b) high porosities (2.0-2.9 vol.\%) (Per88-1). The 
brighter areas in forsterite grains have higher nickel concentration than the other areas. Fo: forsterite, P: pore fluids.

Fig. 5. (a) The mean grain size $G$ and (b) GB density $\rho$ in dunites plotted against the annealing time $t$. The open and solid circles represent the mean grain sizes of the SGG samples having low and high (Per40-7) porosities, respectively. The triangle represents the mean grain sizes of the FGG samples. The dashed and solid lines represent the best fits based on Eqs. (6) and (7) for the mean grain sizes of the SGG samples with low porosity and FGG samples, respectively. The dot-dashed line represents the grain growth of forsterite in the dunite under the same experimental conditions (Ohuchi and Nakamura 2007b). The capsule design used for Per40-7 was the same as that in Ohuchi and Nakamura (2007b).

Fig. 6. Representative Ni-concentration profiles in large forsterite grains $(\sim 100 \mu \mathrm{m})$ contacted to the interface with the capsule in the Per40-7 sample. The profiles were obtained from the area which was $\sim 50 \mu \mathrm{m}$ off the nearest GB. The solid, short-dashed, and long-dashed curves represent the best fits based on Eq. (4). The diffusivity for each profile is also shown (error is within $\pm 1 \mathrm{E}-19 \mathrm{~m}^{2} / \mathrm{s}$ ).

Fig. 7. Representative X-ray element maps of nickel in the SGG (Per87-1: 166h) and FGG (88-1: 49h) samples. The brightness represents the nickel concentration from $\sim 0$ 
wt. $\%$ (the darkest area) to $\sim 10 \mathrm{wt} . \%$ (the brightest) in the dunites.

Fig. 8. The average Ni-concentration profiles across the central area of the samples. The profiles are perpendicular to the long side of the capsules. (a) The SGG samples with low porosities, (b) the SGG sample with a high porosity (Per40-7), and (c) the FGG samples. The solid, short-dashed, long-dashed and thick solid lines in Fig. 8a represent the runs for 2 (Per86-1), 8 (Per84-1), 72 (Per83-1) and 166 hours (Per87-1), respectively. The solid, short-dashed and long-dashed lines in Fig. 8c represent the runs for 4 (Per90-1), 23 (Per78-1), and 49 hours (Per88-1), respectively.

Fig. 9. BSE images (a, d), nickel concentration maps (b, e), and electron backscatterd diffraction (EBSD) maps $(\mathrm{c}, \mathrm{f})$ in the representative SGG and FGG samples (Per40-7 and 88-1, respectively). The images shown in Figs. 9a-c and d-f are from Per40-7 and 88-1 samples, respectively. The nickel concentration increases from $\sim 0$ (the darkest area) to $\sim 2$ wt. $\%$ (the brightest) in Figs. $9 \mathrm{~b}$ and e. The GBs shown by arrows in Fig. 9c are low Ni-concentration GBs (LNGBs). The grain marked by * was plucked during the re-polishing for the element mapping and the BSE image observation after the EBSD mapping.

Fig. 10. BSE images and Ni-concentration profiles across GBs. The profiles have a maximum of Ni-concentration (a) at a GB in the SGG sample (Per87-1), (b) in the 
interior of a grain in the SGG sample (Per87-1), and (c, d) those have more than two maxima in the FGG sample (Per88-1). (e) No Ni-enrichment was detected in the LNGBs in the SGG samples (Per40-7), which was identified by the EBSD analysis. The dotted lines in Figs.10a-d represent the position of present GBs. The dotted line in Fig. 10e represents the LNGB shown in Fig. 9c. A profile having a symmetric pattern across a GB, which is supposed to be a stationary GB, is also shown by open circles in Fig.10e.

Fig. 11. The frequency distributions of the misorientation angles of (a) all the GBs in the SGG samples (Per40-7) and (b) all the GBs in the FGG samples (Per88-1). The theoretical distribution for the randomly oriented GBs (Grimmer, 1979) is shown in the dashed curves. The $N$ stands for the number of the GBs analyzed.

Fig. 12. The $\gamma$-values of the samples plotted against the annealing time. The symbols are the same as in Fig. 5a. The dashed curve represents the best fit based on Eq. (9). The dot-dashed line represents the critical $\gamma$-value $(=1)$ for the dominant Ni-enrichment mechanism, above which GBM is more effective than lattice diffusion (i.e., $V_{g b} \cdot t>$ $\left.\left(D_{l} \cdot t\right)^{1 / 2}\right)$

Fig. 13. The Ni-concentration profiles across (a) the SGG (Per83-1, 84-1, 85-1, 86-1, and 87-1) and (b) the FGG samples (Per78-1, 88-1, and 90-1) plotted in terms of $\ln C / C_{0}$. The lines represent the best fits based on Eq. (5). The numbers in parentheses show the 
slope of the best-fit lines.

Fig. 14. The average $\mathrm{NiO}$ concentration in the area between the depth $y=20$ and 700 $\mu \mathrm{m}, C_{20-700}$, plotted against (a) the GBM distance during the annealing, $V_{g b} \cdot t_{a}$, and (b) $\gamma$. The dashed and solid lines represent the best fits for the relation between $V_{g b} \cdot t_{a}$ and $C_{20-700}$ in the SGG and FGG samples, respectively. The symbols are the same in as Fig. 5 a.

Fig. 15. The volume fraction profile of the Ni-rich region across (a) the SGG samples having low porosity (Per83-1, 84-1, 86-1, and 87-1), (b) the SGG sample having high porosity (Per40-7), and (c) the FGG samples (Per78-1, 88-1, and 90-1). The numbers in parentheses stand for the values of the threshold concentration $C_{t h}$ used for the analysis (in wt.\% NiO).

Fig. 16. The average GB velocity, $v_{g b}$, estimated based on the volume fraction of Ni-rich regions (a), and the $v_{g b} / V_{g b}$ ratio (b), plotted against the average GB velocity, $V_{g b}$ calculated from Eq. (8) and grain growth parameters. The symbols are the same as in Fig. 5a. The dashed line in Fig. 16a represents the slope of $v_{g b} / V_{g b}=1$.

Fig. 17. The ratio $C_{20-700} / C^{\prime}{ }_{20-700}$ plotted against (a) the annealing time and (b) $\gamma$. The symbols are the same as in Fig. 5a. 
Fig. 18. Relationships between $\gamma$ and mean grain size $G$ of the forsterite in dunite and wehrlites (a) under dry and water-saturated conditions for Ni-Mg interdiffusion (dry: bold gray lines; wet: thin lines) and (b) under dry conditions for oxygen (bold gray lines) and silicon self-diffusion (thin lines). The calculation was made by substituting into Eq. (11) the values of $n$ and $k$ for dunite and wehrlites at $1200{ }^{\circ} \mathrm{C}$ and $1.2 \mathrm{GPa}$ under dry (Ohuchi and Nakamura 2007a) and water-saturated conditions (dunite: this study; wehrlites: Ohuchi and Nakamura 2007b). The diffusion coefficients used for the calculations are Ni-Mg interdiffusion $1200{ }^{\circ} \mathrm{C}$ and $1.2 \mathrm{GPa}\left(D_{l, N i-d r y}=9.4 \cdot 10^{-18} \mathrm{~m}^{2} / \mathrm{s}\right.$ : dry conditions; $D_{l, N i \text {-wet }} 2.4 \cdot 10^{-18} \mathrm{~m}^{2} / \mathrm{s}$ : wet conditions), and oxygen and silicon self-diffusion at $1200{ }^{\circ} \mathrm{C}$ and $1.2 \mathrm{GPa}$ under dry conditions $\left(D_{l, O-d r y}=2.3 \cdot 10^{-21} \mathrm{~m}^{2} / \mathrm{s}\right.$; $D_{l, S i-d r y}=5.4 \cdot 10^{-24} \mathrm{~m}^{2} / \mathrm{s}$ ). The diffusion coefficients were calculated using the reported values of pre-exponential parameters and the activation energy (Ni-Mg interdiffusion under dry conditions: Morioka 1981; oxygen and silicon self-diffusion: Dohmen et al. 2002), and the apparent activation volume $\left(7.0 \mathrm{~cm}^{3} / \mathrm{mol}\right.$ : Holzapfel et al. 2007). The solid, dashed, and dot-dashed lines represent the $\gamma-G$ relationships in the dunite and wehrlites having 70 and 50 vol.\% of forsterite (w70 and w50), respectively. 


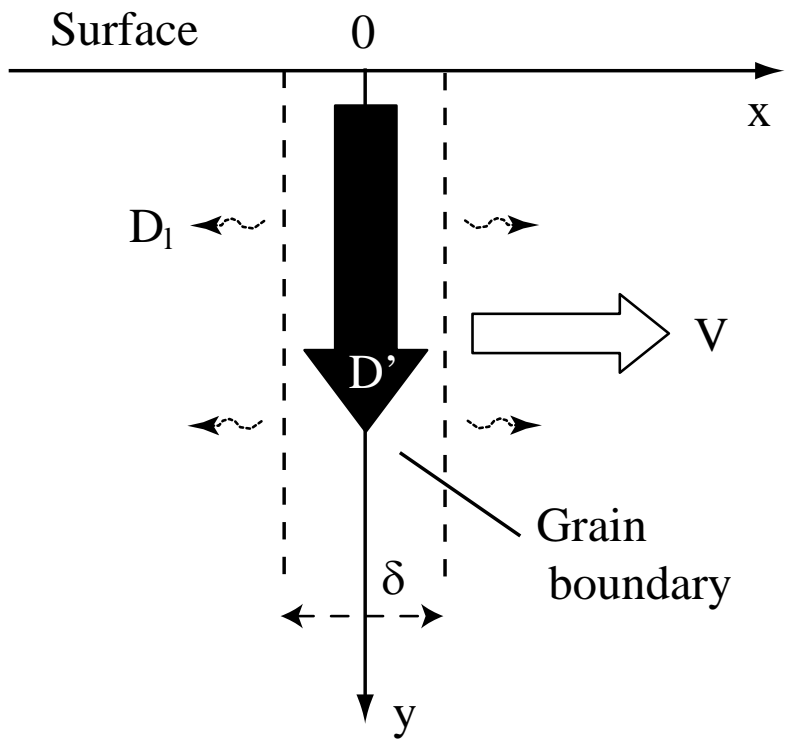

Fig. 1.

Ohuchi et al. 

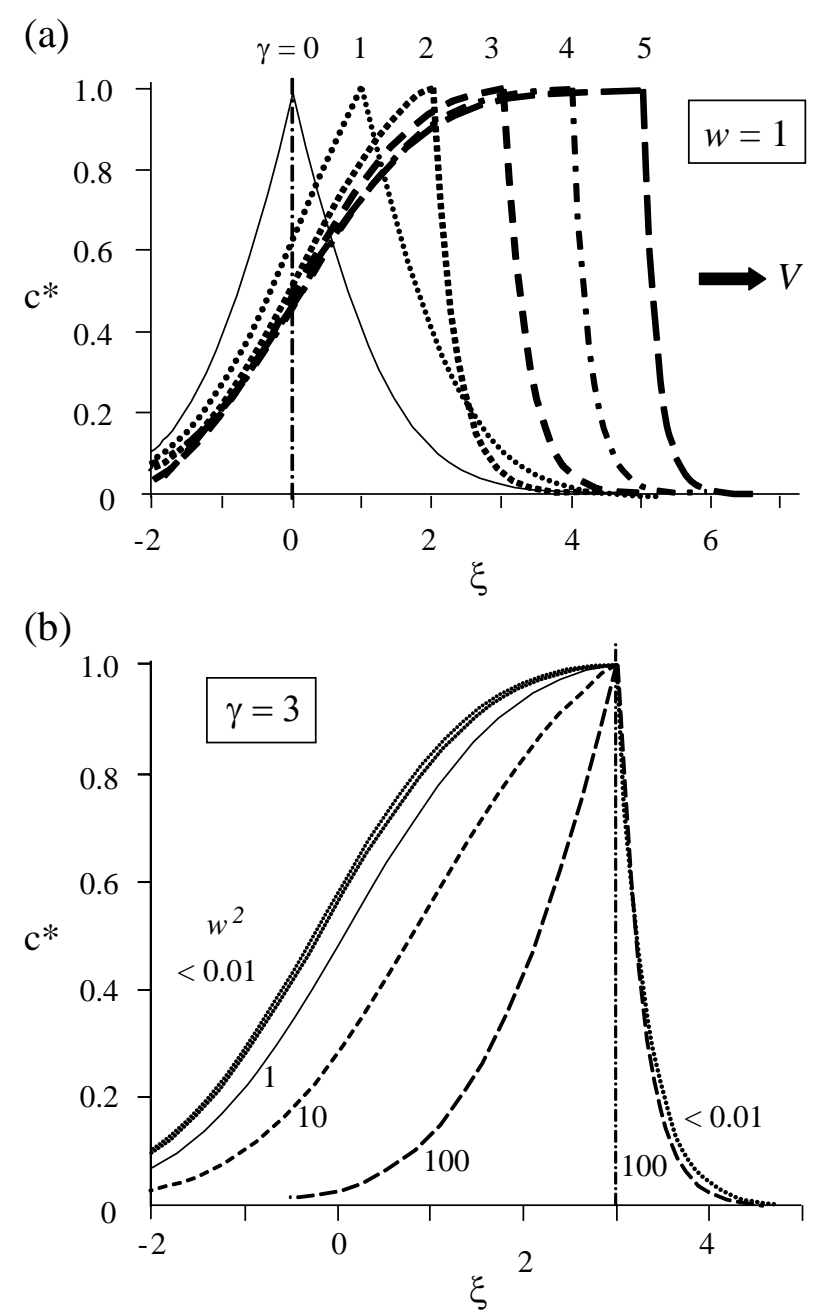

Fig. 2.

Ohuchi et al. 
(a)

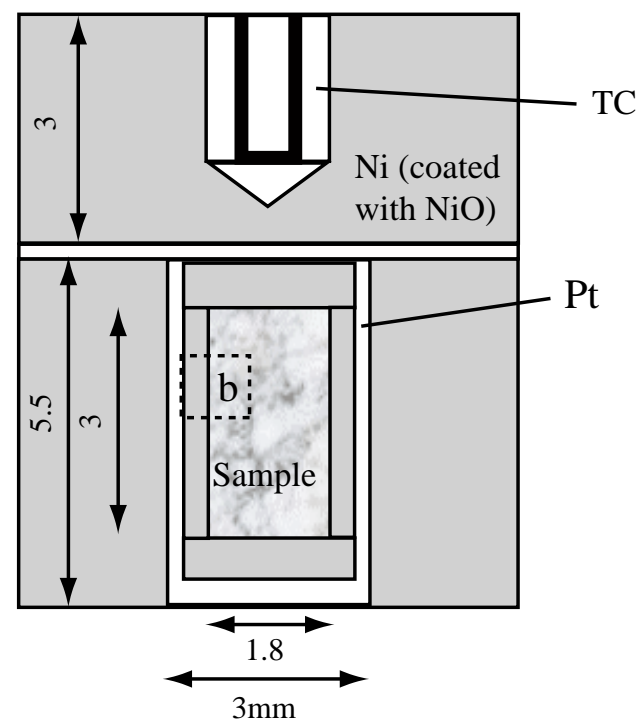

(b)

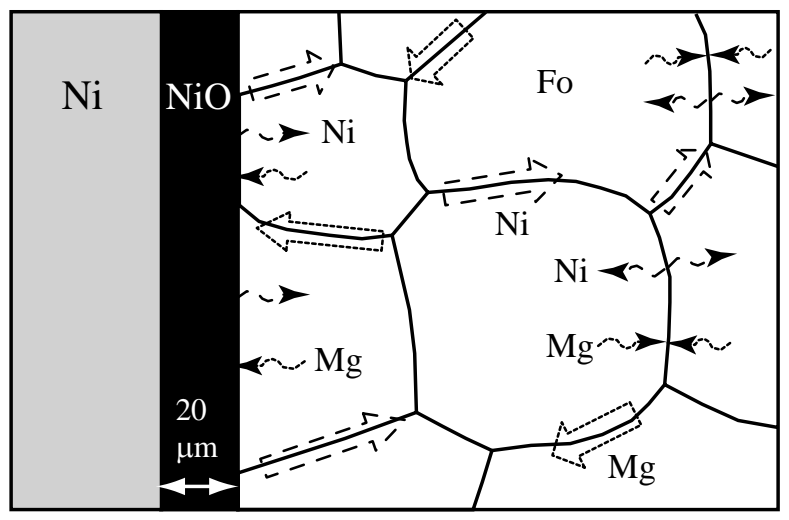

Fig. 3.

Ohuchi et al. 

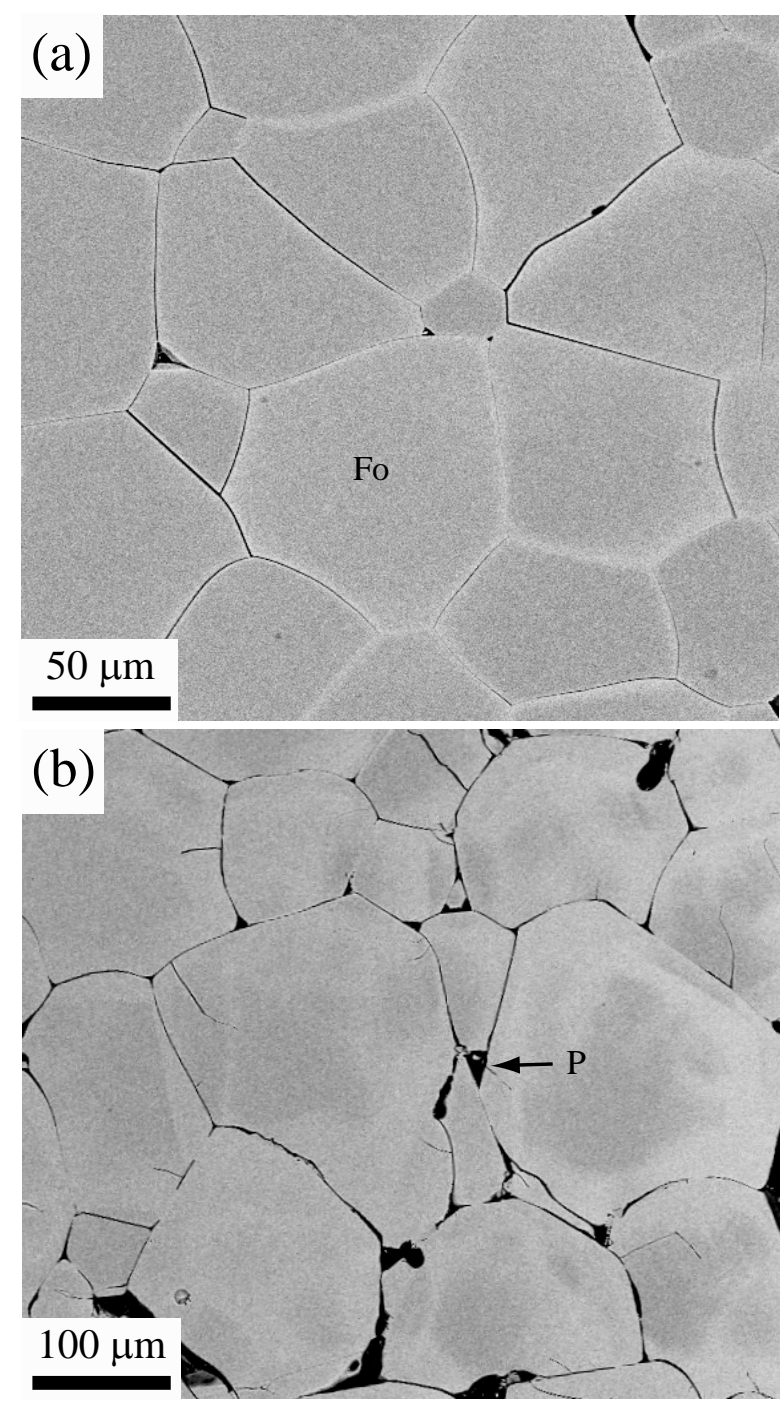

Fig. 4.

Ohuchi et al. 

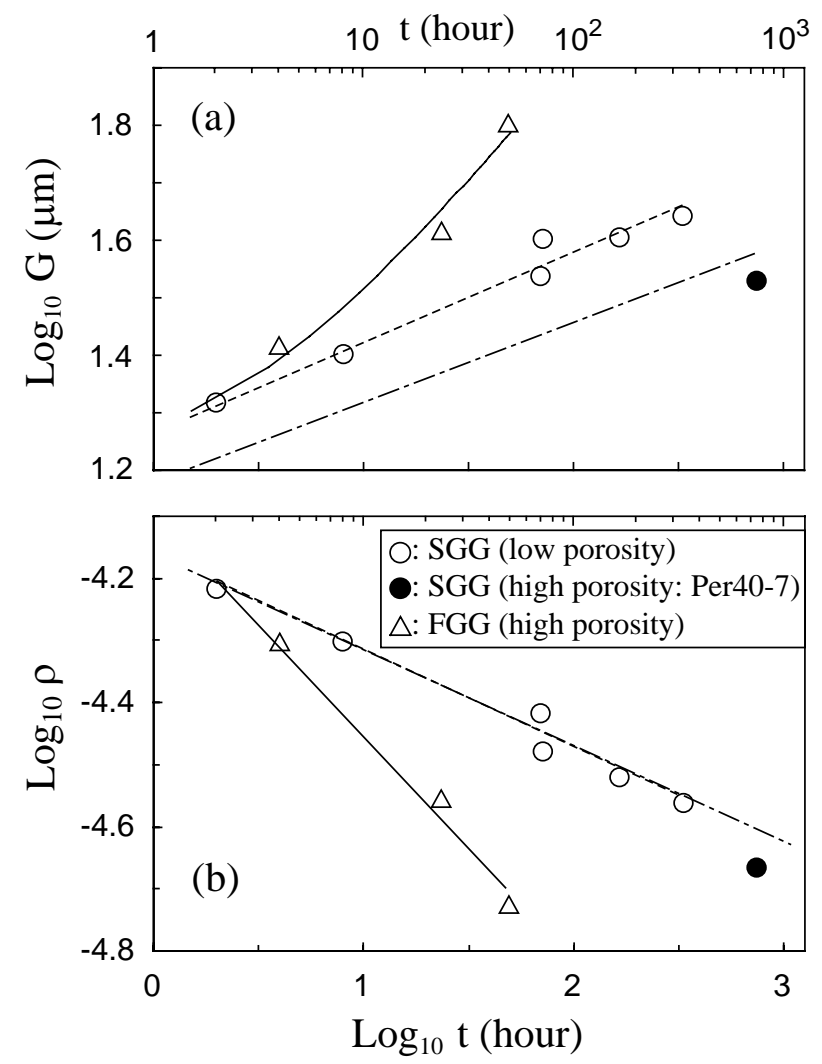

Fig. 5.

Ohuchi et al. 


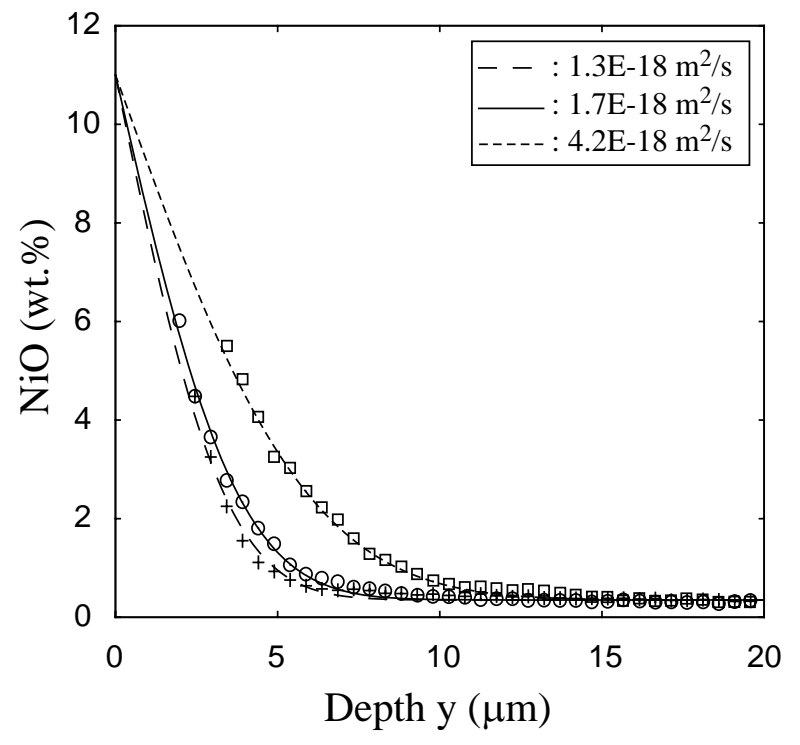

Fig. 6.

Ohuchi et al. 

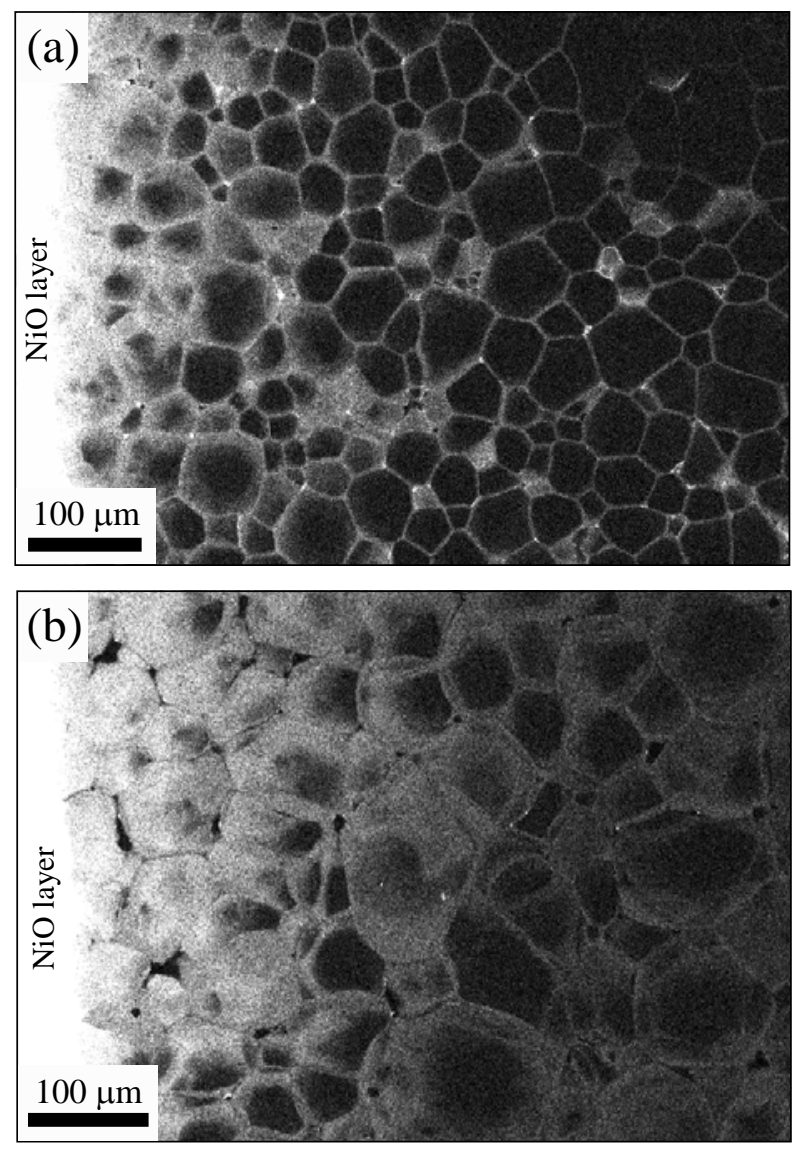

Fig. 7.

Ohuchi et al. 

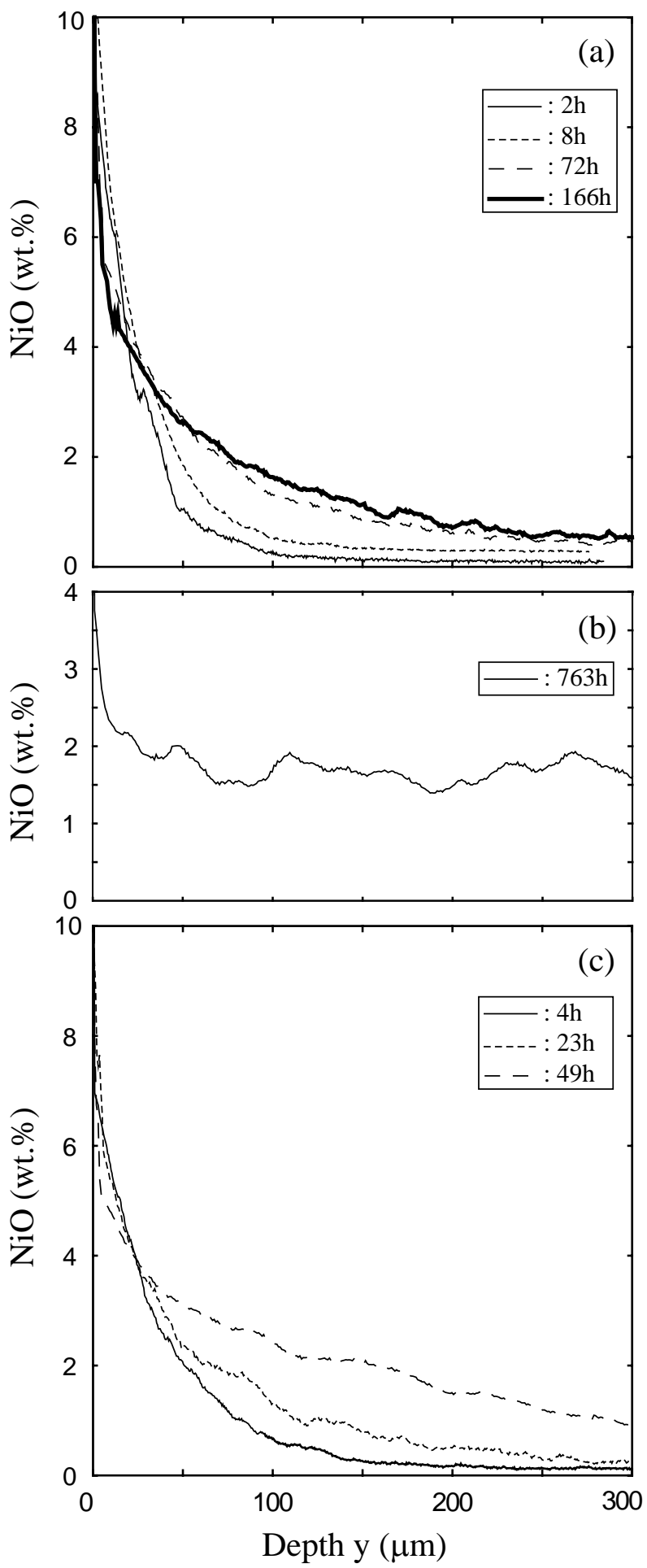

Fig. 8.

Ohuchi et al. 

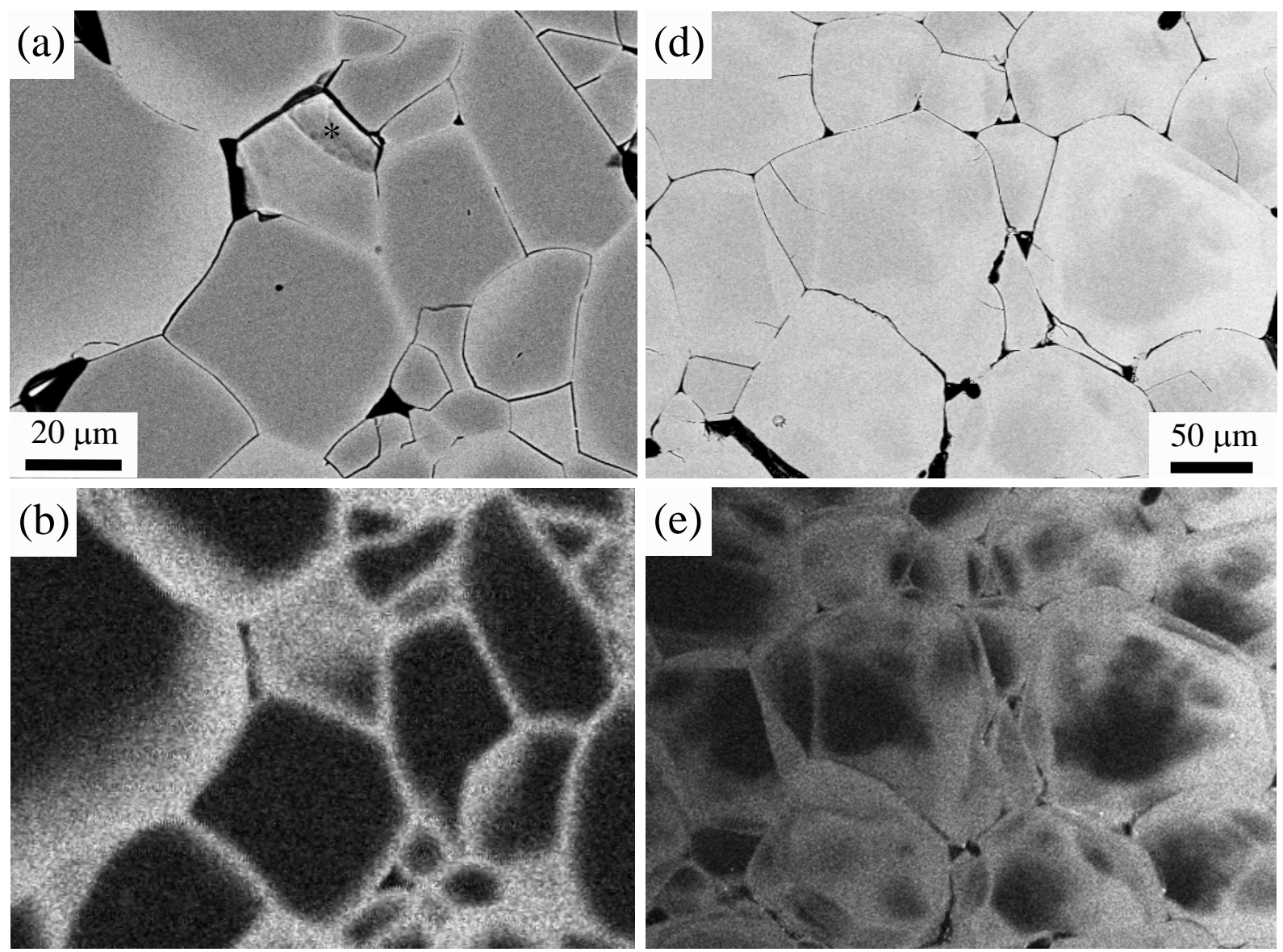

(c)
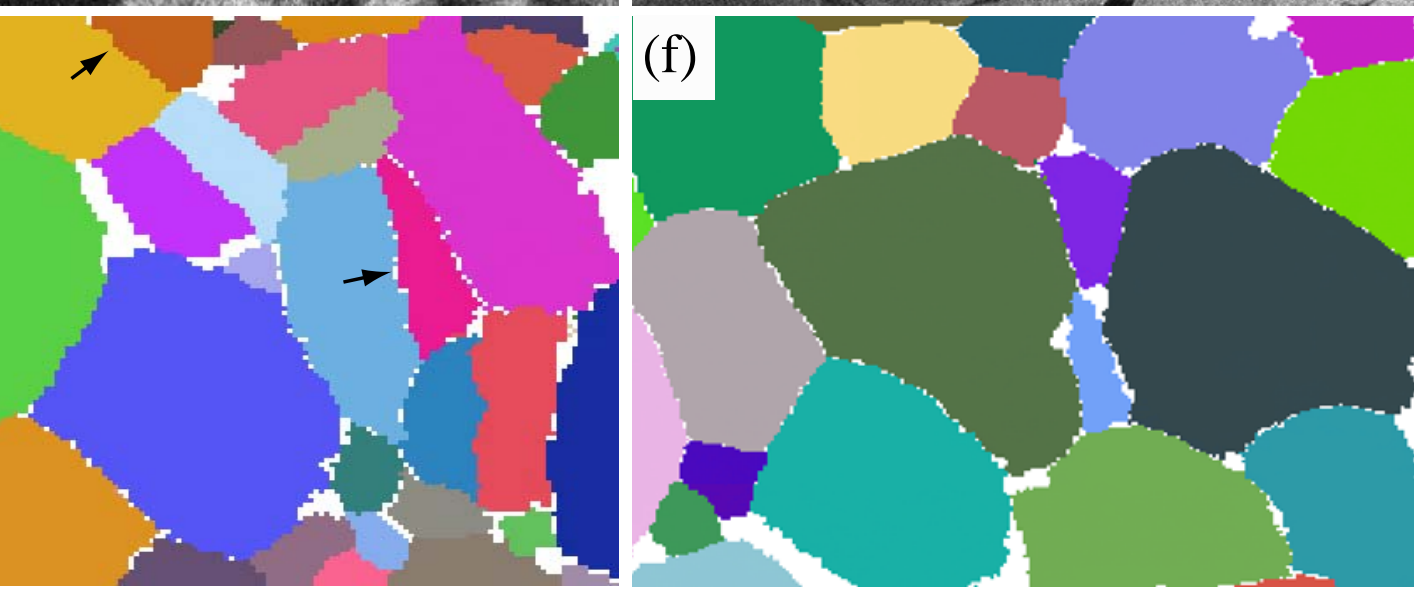

Fig. 9.

Ohuchi et al. 

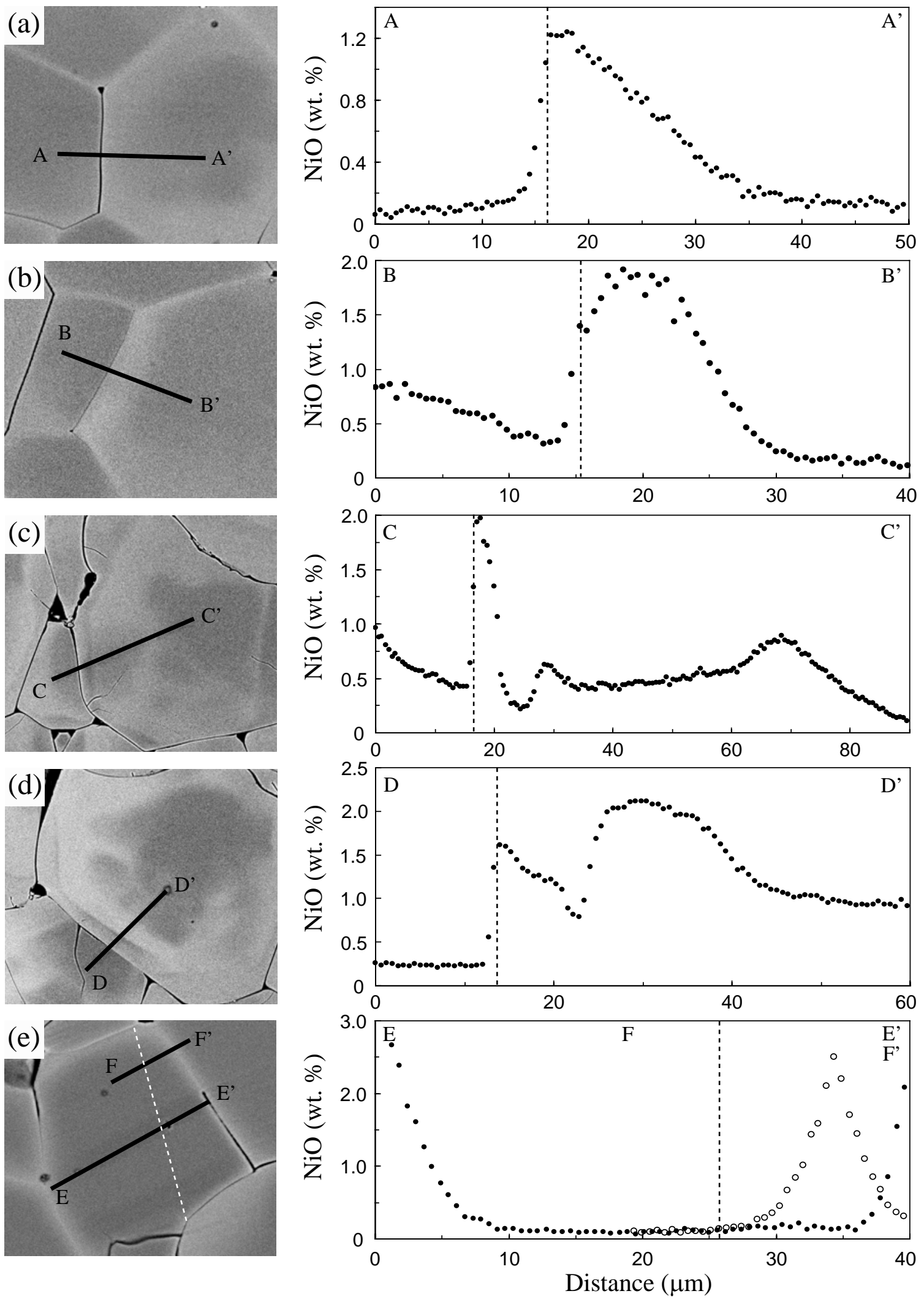

Fig. 10.

Ohuchi et al. 

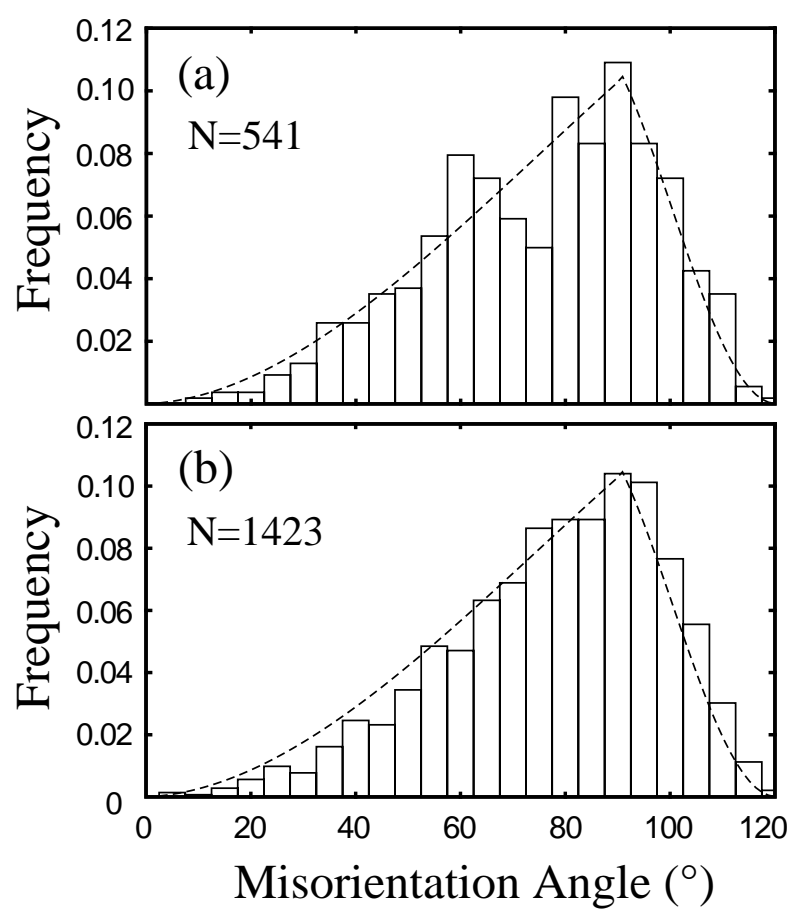

Fig. 11.

Ohuchi et al. 


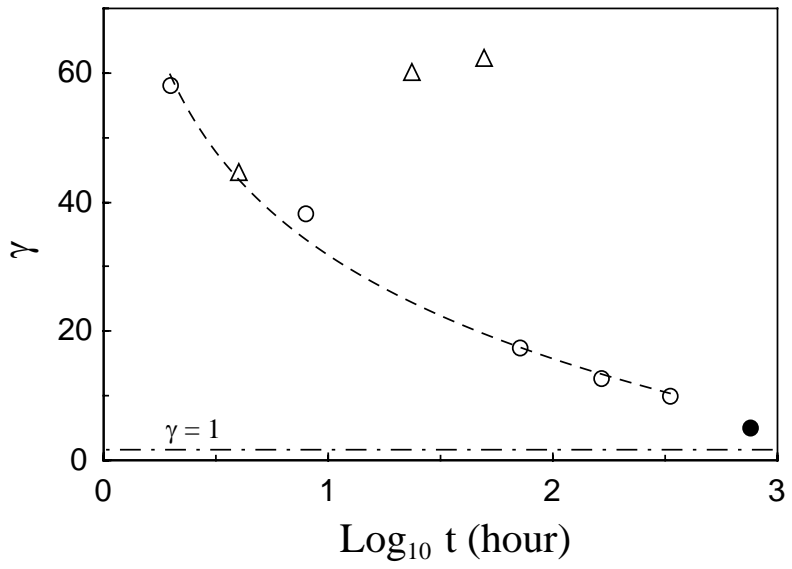

Fig. 12.

Ohuchi et al. 

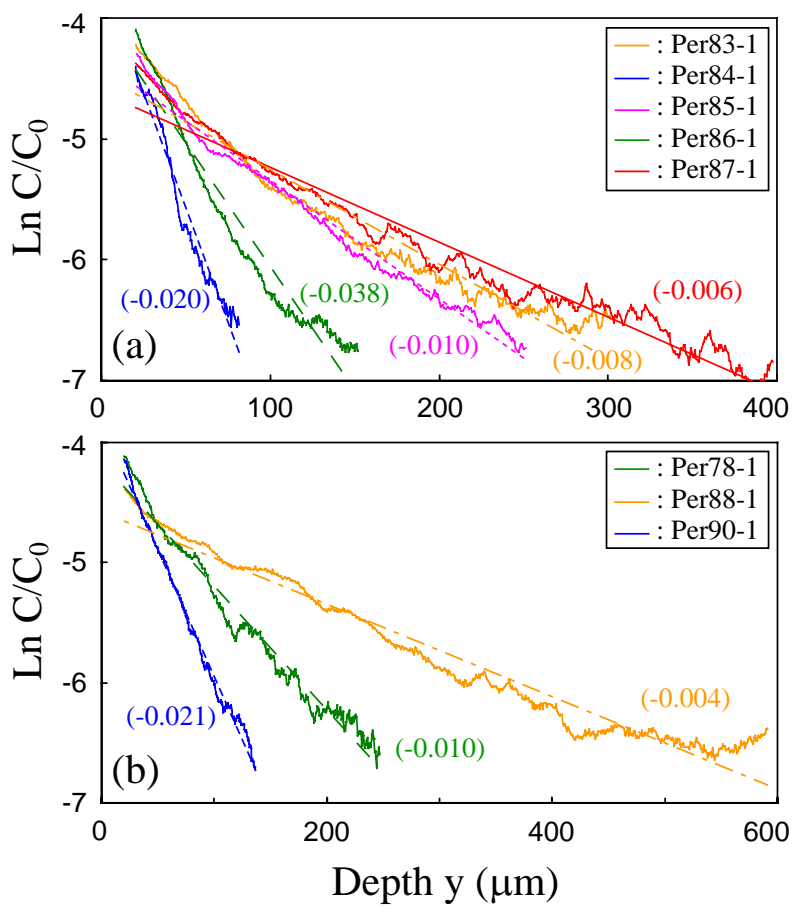

Fig. 13.

Ohuchi et al. 


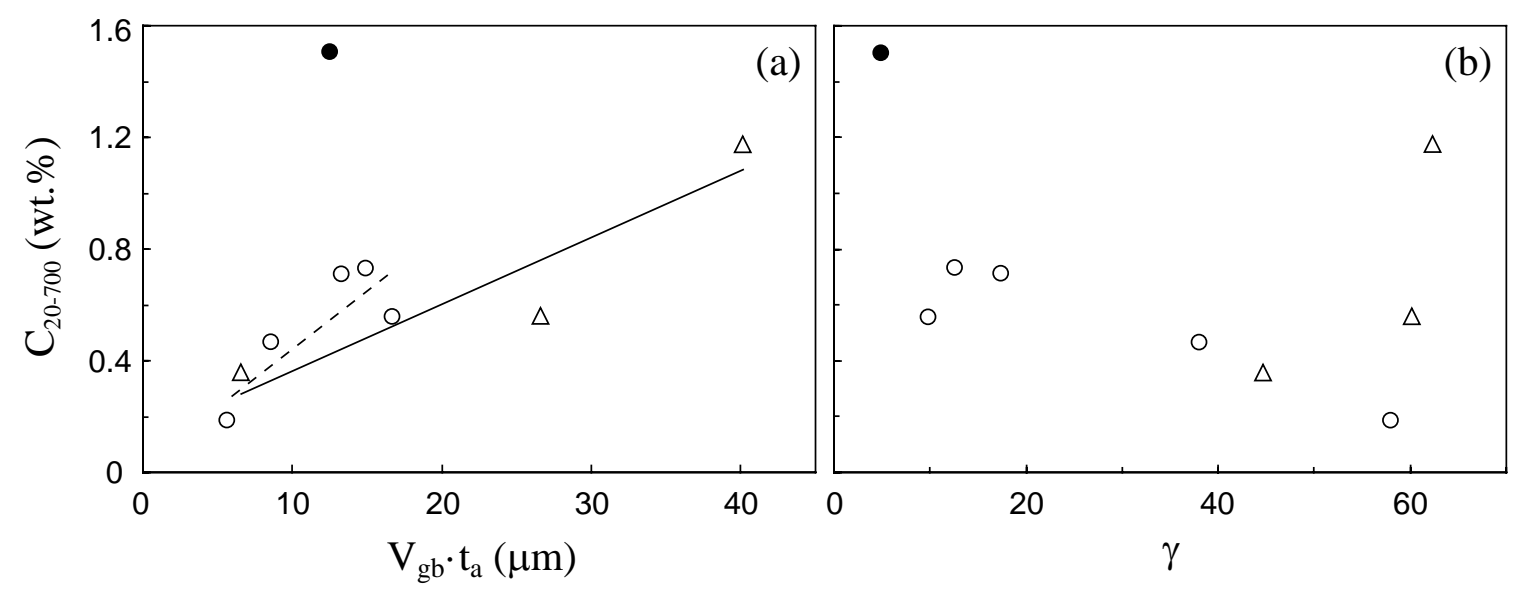

Fig. 14.

Ohuchi et al. 


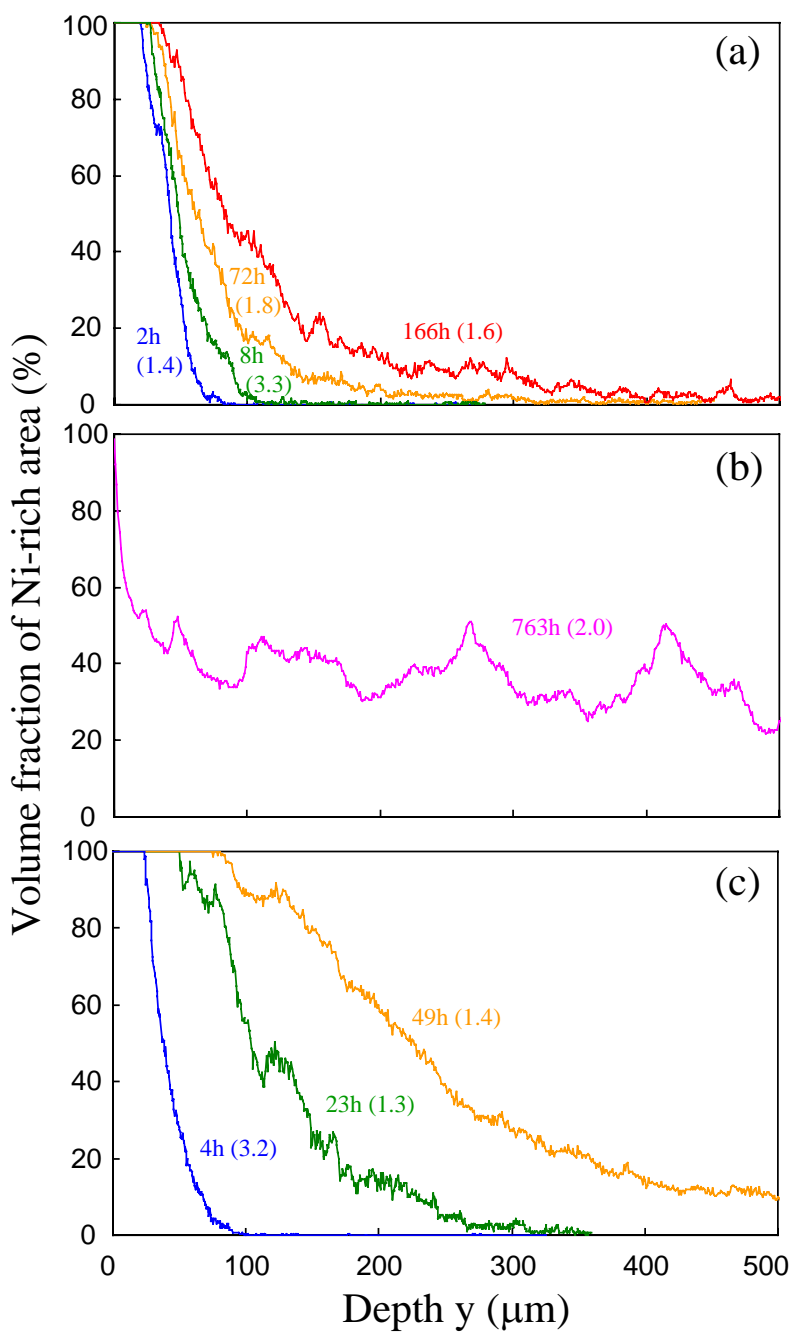

Fig. 15.

Ohuchi et al. 

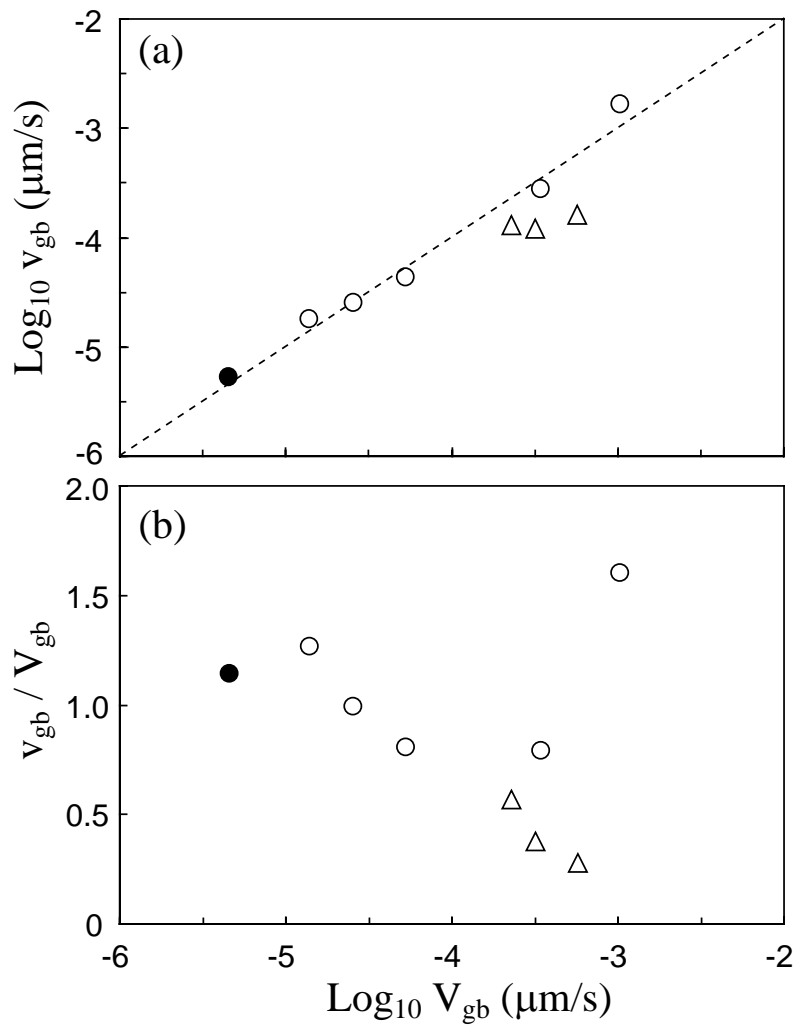

Fig. 16.

Ohuchi et al. 


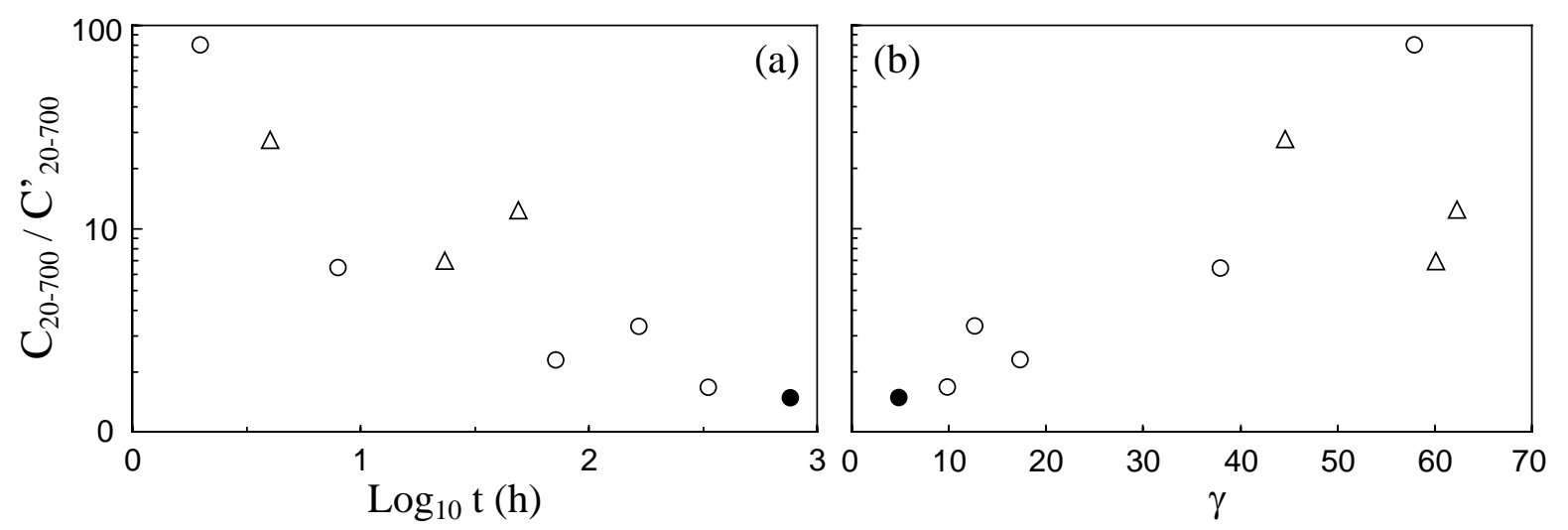

Fig. 17.

Ohuchi et al. 

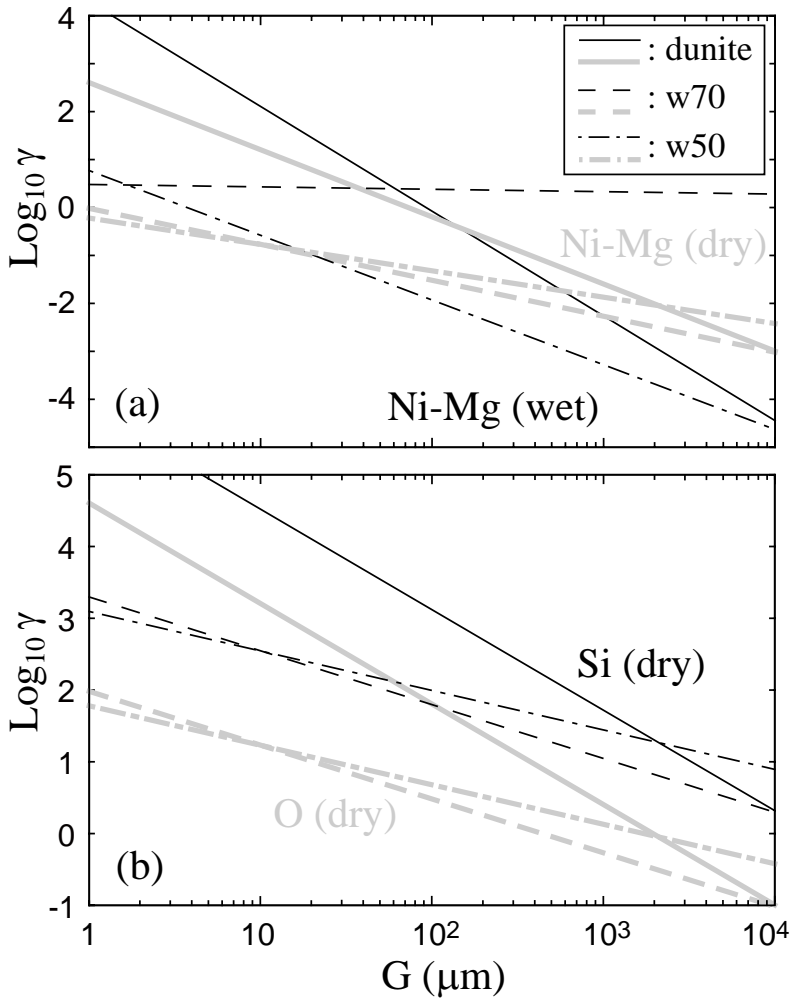

Fig. 18.

Ohuchi et al. 
Table 1

Summary of run information

\begin{tabular}{|c|c|c|c|c|c|c|c|}
\hline Run no. & $t^{\mathrm{a}}(\mathrm{h})$ & $\begin{array}{l}\text { Added water }{ }^{\mathrm{b}} \\
\text { (wt.\%) }\end{array}$ & $\begin{array}{l}\text { Porosity }{ }^{\mathrm{c}} \\
(\mathrm{vol.} \%)\end{array}$ & $\begin{array}{l}\text { Water content }{ }^{\mathrm{d}} \\
\text { (wt. ppm } \mathrm{H}_{2} \mathrm{O} \text { ) }\end{array}$ & $\begin{array}{l}G_{F o}{ }^{\mathrm{e}} \\
(\mu \mathrm{m})\end{array}$ & $\begin{array}{l}\text { abnormal grains } \\
\text { (vol. \%) }\end{array}$ & $\begin{array}{l}\text { Grain boundary } \\
\text { density }\left(\times 10^{-5}\right)\end{array}$ \\
\hline \multicolumn{8}{|c|}{ Slow grain growth (SGG) samples } \\
\hline Per82-1 & 69 & 2.0 & 0.2 & $756 \pm 67$ & 34.5 & 0 & 3.8 \\
\hline Per83-1 & 72 & 2.0 & 0.5 & $427 \pm 39$ & 40.0 & 0 & 3.3 \\
\hline Per84-1 & 8 & 2.0 & 1.1 & $708 \pm 66$ & 25.1 & 0 & 5.0 \\
\hline Per85-1 & 335 & 2.0 & 0.3 & $483 \pm 81$ & 43.9 & 0 & 2.7 \\
\hline Per86-1 & 2 & 2.0 & 0.9 & $617 \pm 30$ & 20.8 & 0 & 6.1 \\
\hline Per87-1 & 166 & 2.0 & 0.4 & $394 \pm 97$ & 40.2 & 0 & 3.0 \\
\hline Per $40-7^{g}$ & 763 & 1.0 & 2.0 & $248 \pm 43$ & 33.9 & 0.40 & 2.1 \\
\hline \multicolumn{8}{|c|}{ Fast grain growth (FGG) samples } \\
\hline Per78-1 & 23 & 3.0 & 2.0 & $681 \pm 45$ & 40.8 & 0 & 2.8 \\
\hline Per88-1 & 49 & 3.0 & 2.9 & $502 \pm 110$ & 63.2 & 0 & 1.9 \\
\hline Per90-1 & 4 & 3.0 & 2.1 & - & 25.9 & 0 & 5.0 \\
\hline
\end{tabular}

${ }^{\mathrm{a}}$ Run duration in hour

${ }^{\mathrm{b}}$ Amount of distilled water added to starting materials

${ }^{c}$ Porosity of the sample (i.e., volume fraction of pore fluid)

${ }^{\mathrm{d}}$ Average water content in the recovered sample

${ }^{\mathrm{e}}$ Mean grain size of forsterite

${ }^{\mathrm{f}}$ Volume fraction of forsterite abnormal grains in all the forsterite grains

${ }^{\mathrm{g}}$ A Pt-lined Ni capsule was used (data from Ohuchi and Nakamura, 2007b) 
Table 2

Grain growth law parameters

$n \quad \log _{10} k\left(\mu \mathrm{m}^{\mathrm{n}} \mathrm{h}^{-1}\right) \quad G_{h}(\mu \mathrm{m}) \quad A\left(\mathrm{~h}^{-\mathrm{B}}\right) \quad B$

\begin{tabular}{llllll}
\hline Slow grain growth (SGG) samples & $6.4 \pm 0.6$ & $8.05 \pm 0.88$ & 1.2 & $-4.16 \pm 0.02$ & $-0.15 \pm 0.01$
\end{tabular}

${\text { Fast grain growth (FGG) samples }{ }^{\mathrm{a}} \quad 2.3 \pm 0.4} \quad 2.37 \pm 0.59 \quad 16.3 \quad-4.10 \pm 0.03 \quad-0.36 \pm 0.03$

${ }^{\mathrm{a}}$ The calculation was made under the assumption that mean grain size of forsterite in the $2 \mathrm{~h}$-annealed FGG sample was as same as that in Per86-1 
Table 3

Estimated values of grain boundary diffusivity of nickel, estimated average grain boundary velocity, and other parameters

\begin{tabular}{|c|c|c|c|c|c|c|c|c|c|c|c|c|}
\hline Run no. & & $\begin{array}{l}d(\ln C) / d y \\
(\text { wt. } \% / \mu \mathrm{m}){ }^{\mathrm{b}}\end{array}$ & $D^{\prime} \delta\left(\mathrm{m}^{3} / \mathrm{s}\right)^{\mathrm{c}}$ & $\begin{array}{l}C_{20-700} \\
\text { (wt. \%) }^{\text {f }}\end{array}$ & $\begin{array}{l}C^{\prime}{ }_{20-700} \\
\text { (wt. \%) }^{\text {g }}\end{array}$ & $C_{20-700} / \mathrm{C}_{20-700}^{\prime}$ & $C_{t h}\left(\right.$ wt. \%) ${ }^{\mathrm{h}}$ & $F_{20-b}\left(\right.$ vol. \%) ${ }^{\mathrm{i}}$ & $\rho_{a}$ & $\begin{array}{l}\log _{10} v_{g b} \\
(\mu \mathrm{m} / \mathrm{s})^{\mathrm{j}}\end{array}$ & $\begin{array}{l}\log _{10} V_{g b} \\
(\mu \mathrm{m} / \mathrm{s})^{\mathrm{k}}\end{array}$ & $v_{g b} / V_{g b}$ \\
\hline \multicolumn{13}{|c|}{ Slow grain growth (SGG) samples } \\
\hline Per82-1 & 17.2 & - & - & - & - & - & - & - & - & - & -4.27 & - \\
\hline Per83-1 & 17.4 & -0.008 & 8.72E-19 & 0.71 & 0.32 & 2.24 & 1.82 & $45.4(b=130)$ & $4.12 \mathrm{E}-05$ & -4.37 & -4.28 & 0.80 \\
\hline Per84-1 & 38.0 & -0.020 & 8.30E-19 & 0.47 & 0.07 & 6.36 & 3.31 & $43.1(b=70)$ & $5.54 \mathrm{E}-05$ & -3.56 & -3.46 & 0.79 \\
\hline Per85-1 & 9.9 & -0.010 & $1.45 \mathrm{E}-19$ & 0.56 & 0.34 & 1.65 & 0.81 & $66.7(b=190)$ & 3.13E-05 & -4.75 & -4.86 & 1.27 \\
\hline Per86-1 & 58.0 & -0.038 & 7.23E-19 & 0.18 & 2E-03 & 80.10 & 1.44 & $72.5(b=55)$ & $6.41 \mathrm{E}-05$ & -2.78 & -2.99 & 1.60 \\
\hline \multirow[t]{2}{*}{ Per87-1 } & 12.7 & -0.006 & $6.61 \mathrm{E}-19$ & 0.73 & 0.22 & 3.30 & 1.63 & $53.8(b=160)$ & 3.58E-05 & -4.60 & -4.59 & 0.99 \\
\hline & & & $6.46 \mathrm{E}-19( \pm 2.92 \mathrm{E}-19)^{\mathrm{d}}$ & & & & & & & & & \\
\hline Per $40-7^{g}$ & 4.9 & - & - & 1.50 & 1.03 & 1.46 & 2.02 & $40.0(b=240)$ & 2.79E-05 & -5.28 & -5.34 & 1.14 \\
\hline \multicolumn{13}{|c|}{ Fast grain growth (FGG) samples } \\
\hline Per78-1 & 60.2 & -0.010 & 2.96E-18 & 0.56 & 0.08 & 6.94 & 1.26 & $37.5(b=290)$ & 3.69E-05 & -3.92 & -3.49 & 0.38 \\
\hline Per88-1 & 62.3 & -0.004 & 1.59E-17 & 1.18 & 0.10 & 12.34 & 1.41 & $62.9(b=350)$ & $2.74 \mathrm{E}-05$ & -3.89 & -3.64 & 0.57 \\
\hline \multirow[t]{2}{*}{ Per90-1 } & 44.6 & -0.021 & $1.27 \mathrm{E}-18$ & 0.36 & 0.01 & 27.46 & 3.23 & $13.3(b=190)$ & $5.94 \mathrm{E}-05$ & -3.80 & -3.24 & 0.28 \\
\hline & & & $6.71 \mathrm{E}-18( \pm 8.01 \mathrm{E}-18)^{\mathrm{e}}$ & & & & & & & & & \\
\hline
\end{tabular}

${ }^{\mathrm{a}} \gamma=V_{g b} \cdot t /\left(D_{l} \cdot t\right)$ : The obtained value of lattice diffusion coefficient of Ni-Mg $\left(D_{l}=2.4 \cdot 10^{-18} \mathrm{~m}^{2} / \mathrm{s}\right)$ was used for the calculation

b, c Calculation was made for the samples having $\gamma$-values higher than 6

d, e Average values of $D_{g b} \cdot \delta$ for SGG and FGG samples, respectively

${ }^{\mathrm{f}}$ Analyzed average $\mathrm{NiO}$ concentration in the area between the depth $y=20$ and $700 \mu \mathrm{m}$

${ }^{\mathrm{g}}$ Average NiO concentration in the area between the depth $y=20$ and $700 \mu \mathrm{m}$ calculated from Eq. (10)

${ }^{\mathrm{h}}$ The threshold NiO concentration in the analyzed area (depth $y=20-b \mu \mathrm{m}$ ). The values of the maximum depth $b$ is as same as $F_{20-b}$

${ }^{\mathrm{i}}$ The maximum depth $b$ which corresponds to the non-dimensional depth $w=0.5$ is shown in parentheses (in $\mu \mathrm{m}$ )

${ }^{\mathrm{j}}$ Average grain boundary velocity calculated from Eq. (2)

${ }^{\mathrm{k}}$ Average grain boundary velocity calculated from Eq. (8) 
Table 4

Grain growth law parameters used for the calculation of the $\gamma-G$ relationship

\begin{tabular}{lll}
\hline & $n$ & $\log _{10} k\left(\mu \mathrm{m}^{\mathrm{n}} \mathrm{h}^{-1}\right)$ \\
\hline Dunite (dry) $^{\mathrm{a}}$ & 4.8 & 5.49 \\
Wehrlite (Fo=70 vol.\%, dry) $^{\mathrm{a}}$ & 3.5 & -0.03 \\
Wehrlite (Fo=50 vol.\%, dry) $^{\mathrm{a}}$ & 3.1 & -0.54 \\
& & \\
Dunite (wet) $^{\mathrm{c}}$ & 6.4 & 8.05 \\
Wehrlite (Fo=70 vol.\%, dry) $^{\mathrm{b}}$ & 2.1 & -0.53 \\
Wehrlite (Fo=50 vol.\%, dry) $^{\mathrm{b}}$ & 4.7 & 0.75 \\
\hline
\end{tabular}

${ }^{a}$ Data from Ohuchi and Nakamura (2007a)

${ }^{\mathrm{b}}$ Data from Ohuchi and Nakamura (2007b)

${ }^{\mathrm{c}}$ Data from this study of SGG samples 